\title{
Gut-Brain Psychology: Rethinking Psychology From the Microbiota-Gut-Brain Axis
}

\author{
Shan Liang ${ }^{1}$, Xiaoli Wu ${ }^{1,2}$ and Feng Jin ${ }^{1 *}$ \\ 'Key Laboratory of Mental Health, Institute of Psychology, Chinese Academy of Sciences, Beijing, China, ${ }^{2}$ University \\ of Chinese Academy of Sciences, Beijing, China
}

Mental disorders and neurological diseases are becoming a rapidly increasing medical burden. Although extensive studies have been conducted, the progress in developing effective therapies for these diseases has still been slow. The current dilemma reminds us that the human being is a superorganism. Only when we take the human self and its partner microbiota into consideration at the same time, can we better understand these diseases. Over the last few centuries, the partner microbiota has experienced tremendous change, much more than human genes, because of the modern transformations in diet, lifestyle, medical care, and so on, parallel to the modern epidemiological transition. Existing research indicates that gut microbiota plays an important role in this transition. According to gut-brain psychology, the gut microbiota is a crucial part of the gut-brain network, and it communicates with the brain via the microbiota-gut-brain axis. The gut microbiota almost develops synchronously with the gut-brain, brain, and mind. The gut microbiota influences various normal

OPEN ACCESS

Edited by:

Sidarta Ribeiro,

Federal University of

Rio Grande do Norte, Brazil

Reviewed by:

Faming Zhang,

Second Affiliated Hospital of Nanjing

Medical University, China

Bruno Bonaz,

Centre Hospitalier Universitaire

de Grenoble, France

*Correspondence:

Feng Jin

jinfeng@psych.ac.cn

Received: 30 April 2018

Accepted: 19 July 2018

Published: 11 September 2018

Citation:

Liang S, Wu X and Jin F (2018)

Gut-Brain Psychology: Rethinking

Psychology From

the Microbiota-Gut-Brain Axis.

Front. Integr. Neurosci. 12:33.

doi: 10.3389/fnint.2018.00033 mental processes and mental phenomena, and is involved in the pathophysiology of numerous mental and neurological diseases. Targeting the microbiota in therapy for these diseases is a promising approach that is supported by three theories: the gut microbiota hypothesis, the "old friend" hypothesis, and the leaky gut theory. The effects of gut microbiota on the brain and behavior are fulfilled by the microbiota-gut-brain axis, which is mainly composed of the nervous pathway, endocrine pathway, and immune pathway. Undoubtedly, gut-brain psychology will bring great enhancement to psychology, neuroscience, and psychiatry. Various microbiota-improving methods including fecal microbiota transplantation, probiotics, prebiotics, a healthy diet, and healthy lifestyle have shown the capability to promote the function of the gut-brain, microbiota-gut-brain axis, and brain. It will be possible to harness the gut microbiota to improve brain and mental health and prevent and treat related diseases in the future.

\footnotetext{
Keywords: gut-brain psychology, microbiota-gut-brain axis, diet, modernization, lifestyle, superorganism, mental disorders, nutritional psychology
}

\section{CURRENT CHALLENGES IN PSYCHOLOGY}

Psychology is a discipline that targets the rules of human psychological phenomena and behavior. Unfortunately, it seems like the more we know about human psychology, the more we realize we do not know. Until recently, not a single mental disorder had an established definite biomarker, either physiological, biochemical, or genetic. The application of psychology seems to lag behind other 
disciplines, and mental illnesses remain medical challenges. In the last few decades, the number of patients with mental disorders and neurologic diseases has increased rapidly, causing a great escalation of medical burden, as shown in Figure 1 (DALYs and Collaborators, 2016, 2017; GBD 2017 Neurological Disorders Collaborator Group, 2017). Although the overall medical burden created by mental disorders exceeded one-fifth of the total, the rates of treatment and recovery were far below those of other diseases (Ledford, 2014; Smith and Torres, 2014). All of these findings suggest that the existing research has neglected the fact that the human being is a superorganism.

\section{RE-RECOGNIZING THE SUBJECT OF PSYCHOLOGY: THE SUPERORGANISM}

Following the development of bioinformatics and gut microbiota research in the 21 st century, scientists have found that the human being is a superorganism carrying billons of microorganisms, such as bacteria, archaea, fungi, viruses, and protozoa, living on its internal and external surfaces (Group, 2008; Limon et al., 2017; Manrique et al., 2017; Wampach et al., 2017). These microorganisms mostly inhabit the skin surface and digestive, respiratory, urinary, and reproductive tracts. Microorganisms amounting to more than $1 \mathrm{~kg}$ inhabit the digestive tract; these are considered to be the most important microorganisms in the human body, and they are collectively called the gut microbiota. The microbiota contains 300-3,000 different species, whose total number exceeds $10^{14}$, which is almost 10 times the total number of human cells; the genes encoded therein surpass 5 million, which is more than 200 times the number of human genes (Human Microbiome Project Consortium, 2012; Burcelin et al., 2013; Sandoval-Motta et al., 2017). Since 2008, Nature has advocated calling the human being "we" rather than "I" because more than $90 \%$ of the total cells and genes of the superorganism are microorganisms. In daily life, individuals living together for a long time usually share many similarities. This phenomenon could be mainly due to the convergence of people's microorganisms (Yatsunenko et al., 2012), since most of human genes are relatively stable after birth. These microorganisms have established interdependent and mutualistic relationships with humans over the long process of evolution; therefore, they are called commensal microbiota (Fraune and Bosch, 2010).

\section{Maturation and Function of the Superorganism Are Modulated by the Commensal Microbiota}

The growth and development of human beings are not only modulated by their own genes, but they are also influenced by their commensal microbiota. Humans provide living space and food for the microbiota and unconsciously regulate the composition and number of microorganisms, while the microbiota impacts the maturation and function of human beings (Ulvestad, 2009). Embryonic development is influenced by maternal gut microbiota, and the development and function of most mammalian systems are also affected by their own commensal microbiota after birth (Manco, 2012; McFall-Ngai et al., 2013).

The gut microbiota is involved in the metabolism and digestive absorption of nutrients; it aids in the digestion of resistant carbohydrates, the decomposition of endogenous and exogenous proteins, the degradation of bile acid, and the synthesis of vitamins and other bioactive compounds (Nicholson et al., 2012; Cabral, 2013). The colonization of the gut microbiota is indispensable for the maturation of the immune system, and its impact is likely to have a critical period, which means that the colonization only works in the critical period and cannot be remedied after that time (Gensollen et al., 2016; Knoop et al., 2017). The maturation of the neuroendocrine system is also regulated by the gut microbiota, and this influence may have a critical period, too (Sudo et al., 2005; Sudo, 2014). Both the maturation and function of the brain and mind are impacted by the gut microbiota (Diaz Heijtz et al., 2011; Borre et al., 2014; Desbonnet et al., 2014; Parashar and Udayabanu, 2016; Vuong et al., 2017).

Meanwhile, the respiratory tract microbiota plays an important role in the development and function of the respiratory system, and abnormal microbiota may be involved in the occurrence of respiratory disease (Man et al., 2017). The skin microbiota not only constitutes the first biological barrier of the organism, but also influences immune function, and skin microbiota abnormalities are closely related to skin disorders, including eczema and psoriasis (Egert et al., 2017). Finally, healthy vaginal microbiota is necessary for female health, and it is beneficial for the development of commensal microbiota in the offspring (Humphries, 2017).

In conclusion, individual maturation and function are strongly linked to commensal microbiota (Collins et al., 2012; McFall-Ngai et al., 2013). Acquiring adequate microbiota can help ensure a healthy and happy human life. When the microbiota is deprived, dysfunction can appear in the digestive system, immune system, endocrine system, nervous system, and even in behavior and cognition (Sudo et al., 2005; Fang and Evans, 2013; Crumeyrolle-Arias et al., 2014).

\section{Dramatic Changes in the Superorganism in Modern Society}

Human society has changed significantly since the industrial revolution, which was followed by tremendous variations in diet, lifestyle, and health care. Although the genes of the human have not changed much, the important component of the superorganism microbiota has undergone tremendous change (Gomez, 2017; Mancabelli et al., 2017). Remote rural areas have experienced relatively small variation over the past century, with the inhabitants having gut microbiota distinct from those of modern city dwellers. Even in developed countries, rural-urban differences in gut microbiota exist. For example, the bacteria that metabolize fiber have decreased, whereas the bacteria that metabolize animal protein and fat have increased in city dwellers; even in people who have moved from villages to cities, the gut microbiota seems to have changed to a more 

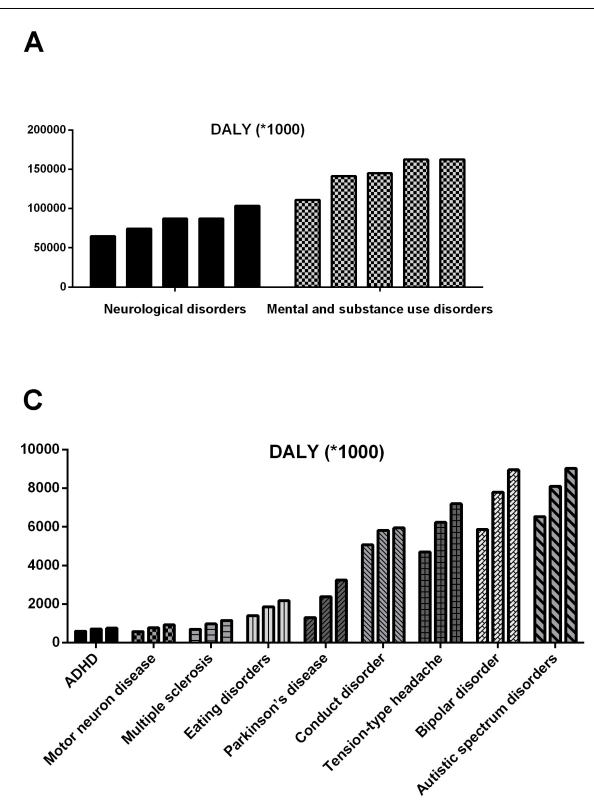

B

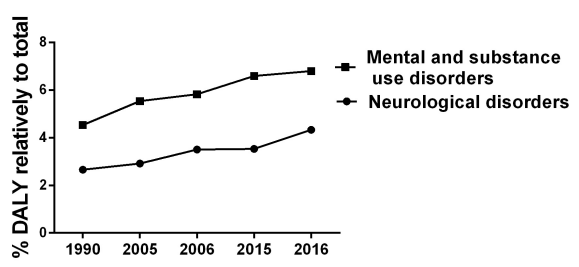

D

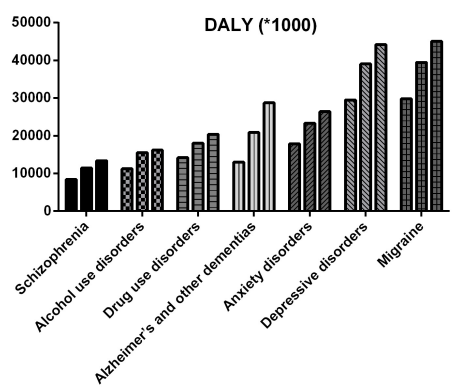

FIGURE 1 | The ever-increasing medical burden induced by mental disorders and neurological diseases (DALYs and Collaborators, 2016, 2017). (A,B) Shows the disability-adjusted life years (DALYs) induced by mental disorders and neurological diseases, respectively. (C,D) Shows the DALYs induced by different diseases in 1990, 2006, and 2016.

urbanized microbiota (De Filippo et al., 2017). Modernization has been changing the microbiota by various means, including diet, lifestyle, and medication (De Filippo et al., 2017; Gomez, 2017; Mancabelli et al., 2017).

\section{Diet Changes}

Diet shapes the gut microbiota, and different foods prompt the proliferation of different microorganisms (Duncan et al., 2007; Wu et al., 2011; Voreades et al., 2014; Shanahan et al., 2017; Singh et al., 2017). Even short-term dietary changes alter the human microbiota (David et al., 2014; Li J. et al., 2017). The human dietincluding dietary structure, dietary habits, and food processinghas experienced great changes following modernization, and these alterations have significantly influenced the gut microbiota (Zarrinpar et al., 2014; Roca-Saavedra et al., 2017; Statovci et al., 2017).

In terms of dietary structure, refined carbohydrates dominate the total food intake; the intake of meat, fat, sugar, and salt has increased rapidly, whereas the intake of dietary fibers has decreased sharply. However, high-fat diets and high refined carbohydrate diets, which are rich in sucrose and fructose, perturb the gut microbiota ( $\mathrm{Hu}$ et al., 2014; Magnusson et al., 2015; Rosas-Villegas et al., 2017). Dietary fibers, which include $\beta$-glucan, arabinoxylans, and resistant starch, are non-digestible polysaccharides that are abundant in whole grains, functionally known as microbiota-accessible carbohydrates (MACs) (Daien et al., 2017; Gong et al., 2018). They are the main source of energy for gut bacteria, and they are essential to maintain human health (Koh et al., 2016; Daien et al., 2017; Williamson, 2017). A long-term low-MAC diet has been found to lead to microbiota extinction, which presented intergenerational effects. The gut microbiota was restored by a high-fiber diet in the first generation, but it was not restored in the subsequent generations (Sonnenburg et al., 2016).

In terms of dietary habits, the number of times people eat at home has reduced significantly, whereas the number of times people eat out and eat snacks has increased rapidly. In food processing, the proportion of fresh food and traditional fermented food has decreased significantly, whereas the proportion of processed food and industrially produced food has increased rapidly (De Filippo et al., 2017; Derrien and Veiga, 2017; Statovci et al., 2017). The food additives, pesticide residues, and drug residues in the food could greatly disrupt the gut microbiota upon entry into the digestive tract (Suez et al., 2014; Chassaing et al., 2015, 2017; Bian et al., 2017; Jiang et al., 2017; Roca-Saavedra et al., 2017). Although most standard additives are harmless to the body, they have effects on the gut microbiota, which have generally been ignored until recently (Roca-Saavedra et al., 2017). In addition to antiseptics such as potassium sorbate and sodium benzoate, other additives also significantly perturb the gut microbiota. Emulsifiers, including hydroxymethyl cellulose and polysorbate 80 , damage the gut microbiota and induce inflammation and metabolic syndrome (Chassaing et al., 2015). Artificial sweeteners, such as saccharin, aspartame, and sucralose, alter the gut microbiota and gut-brain function, inducing glucose intolerance (Suez et al., 2014; Bian et al., 2017).

In short, it has become increasingly difficult for a person to acquire adequate commensal microbiota from food, and the significant changes in diet in recent decades may be the cause of the convergent evolution of the gut microbiota in the modern 
urban population (De Filippo et al., 2017; Derrien and Veiga, 2017).

\section{Lifestyle Changes}

Human beings live in a bacterial world, and lifestyle factors such as environment and habit determine the species and the number of bacteria that one carries (Rook, 2009; Shanahan, 2009; De Filippo et al., 2017; Jin et al., 2017; Velmurugan et al., 2017). The living environment has changed since modernization. More and more people have migrated from villages to cities and/or shifted from working outdoors to working indoors; as a result, there are fewer and fewer opportunities for people to touch pollutionfree soil and water to acquire harmless microorganisms (Rook, 2009; Shanahan, 2009; Jin et al., 2017; Velmurugan et al., 2017). Lifestyle habits have changed as well. Instead of delivering babies vaginally, modern pregnant women more frequently undergo cesarean sections. Additionally, modern mothers often do not have enough time to breastfeed for a variety of reasons, such as work, so their children are usually fed processed formula milk powder. Moreover, physical activity levels have been significantly reduced with the convenience of modern life. The circadian rhythm is also often disrupted; the average sleep duration has decreased, and day and night inversion has become increasingly common. The changes in delivery mode, feeding patterns, physical activity, and circadian rhythm could all impact the commensal microbiota (Shanahan, 2009; Di Mauro et al., 2013; Hallgren et al., 2016; Khalyfa et al., 2017; Paschos and FitzGerald, 2017; Zhao and Zhang, 2017).

\section{Health Care Changes}

Health care conditions have been greatly improved since modernization, but overtreatment and excessive hygiene have perturbed the commensal microbiota (Armelagos, 2009; Rook, 2009; Blaser, 2016; Two et al., 2016; Joshipura et al., 2017; Rook et al., 2017). Although drugs, including antibiotics, may be harmless to the human body, they can damage the commensal microbiota (Blaser, 2016). As public health standards have been enhanced, disinfection and sterilization have become more and more common in the workplace and at home. Personal hygiene standards have also risen; the frequency of brushing teeth, washing hands, and washing clothes have increased, which means greater daily use of chemical products and more and more overly clean people (Two et al., 2016; Joshipura et al., 2017).

\section{Great Transformation of Disease Types}

In brief, the tremendous changes in diet, lifestyle, and health care have deprived modern people of opportunities to gain adequate environmental and foodborne microorganisms. All of these factors have changed the superorganism. The biggest alterations in the human body from the times of the agricultural society to the industrial society may not be in the human genes, but in the commensal microbiota with which we coexist (Gomez, 2017; Mancabelli et al., 2017). The symbiotic relationship between humans and microorganisms has been established over millions of years of evolution by natural selection, and it is relatively exclusive. For example, only the gut microbiota of mice can facilitate their own immune maturation, whereas those of humans and rats cannot (Ferreira and Veldhoen, 2012). The new human gut microbiota was not established through longterm natural selection, and it easily conflicts with the human body. Thus, more and more human diseases have appeared that deviate from Hardy-Weinberg Equilibrium, and they cannot be explained by the genes present in humans alone (Lerner et al., 2017; Neish et al., 2017; Rook et al., 2017).

The changes in the species and the construction of the commensal microbiota inevitably cause alterations in human function. For example, more and more modern city dwellers present intolerance to traditional foods, including gluten, milk, and eggs (Derrien and Veiga, 2017; Skypala, 2017; Tordesillas et al., 2017). While traditional infectious diseases that prevailed in the agricultural society have rapidly decreased, autoimmune diseases, such as allergies and asthma; cardiovascular diseases, such as hypertension; metabolic diseases, including diabetes and fatty liver; mental disorders, including depression and anxiety; and neurodegenerative diseases, such as Alzheimer's disease and Parkinson's disease, have all increased significantly. This is the epidemiological transition that modern people are experiencing (Armelagos et al., 2005; Becker, 2007; Rook and Lowry, 2008; Armelagos, 2009; Elliott and Weinstock, 2009; Bloomfield, 2013; DALYs and Collaborators, 2017).

The most complex and important component of the commensal microbiota is the gut microbiota, which is one of the most biodiverse ecosystems in the world (Montiel-Castro et al., 2013). The existence and construction of this ecosystem are closely related to human health and disease. It is believed that the microbiota plays a crucial role in the pathophysiology of digestive diseases, metabolic diseases, immune diseases, and neurodevelopmental diseases (Backhed, 2010; Clemente et al., 2012; Eloe-Fadrosh and Rasko, 2013). Targeted therapy of the gut microbiota will be an important and promising field in the future (Petrof et al., 2013; Wallace and Redinbo, 2013; Young, 2017).

\section{GUT MICROBIOTA, GUT-BRAIN, AND GUT-BRAIN PSYCHOLOGY}

\section{Gut-Brain}

The gut is the biggest digestive organ, immune organ, and endocrine organ of the human body, and it also possesses a nervous system [the enteric nervous system (ENS)], which is relatively independent of the brain. During the fetal period, neural crest cells almost simultaneously differentiate into the central nervous system (CNS) and ENS. The ENS presents many similarities with the brain in terms of neuronal components, neurotransmitters, and functional independence (Petrof et al., 2013; Wallace and Redinbo, 2013; Young, 2017). The gut is a microbial organ with $90-95 \%$ of its total cell number consisting of microorganisms. The gut provides living space and food for microorganisms, while the microbiota influences the development and function of the gut. The gut and gut microbiota work together to perform the tasks of digestion, immune and endocrine functions, and neurotransmission (Forsythe et al., 2010; Lyte, 2010; Nicholson et al., 2012; Sudo, 2014; Ridaura and Belkaid, 2015). We call this microbial organ gut-brain because, 
unlike other peripheral organs, it can work without instructions from the brain, and this specificity can easily be found in the persistent vegetative state (Liang et al., 2012; Liang et al., 2018a,b). The gut-brain not only completes its local function, but also regulates human behavior and cognition, similar to the brain (Grenham et al., 2011; Collins et al., 2012; Mayer et al., 2014a; Foster et al., 2016). Gut-brain psychology is the discipline of studying the relationship between the gut-brain and mind. Research in this field has increased rapidly over the last decade.

\section{Gut Microbiota Regulates the Development of Brain and Behavior}

As shown in Figure 2, the gut microbiota develops almost simultaneously with the brain and psychology. It not only regulates the structure and function of the gut-brain, but also influences the development of the brain and behavior (Luczynski et al., 2016; Sharon et al., 2016; Kundu et al., 2017; Vuong et al., 2017; Carlson et al., 2018), and microbiota disturbances at different stages can induce different brain and mental disorders (Borre et al., 2014; Gur et al., 2015; Sampson and Mazmanian, 2015; Dinan and Cryan, 2017).

The human gut microbiota does not appear suddenly, but experiences a gradual growth from simple to complex, then tends to stabilize, and finally declines slowly (Garcia-Pena et al., 2017; Vuong et al., 2017). The fetus probably starts to come in contact with the microorganisms early in the womb, at which time the microbiota is mainly determined by maternal physiological and psychological conditions, diet, drugs, and so forth (Lim et al., 2016). The early microbiota of the newborn is largely determined by the delivery mode. Vigorous newborns typically gain many microorganisms, such as Lactobacillus, from the maternal vagina, whereas neonates born by cesarean gain microorganisms, such as Clostridium, from the air and the maternal skin (Penders et al., 2006; Bokulich et al., 2016; von Mutius, 2017). Feeding patterns regulate the microbiota in the next stage. Breastfed infants obtain more Bifidobacterium and Lactobacillus, whereas infants fed with formula milk obtain more Enterococcus and Enterobacterium (Penders et al., 2006; Bokulich et al., 2016; Kundu et al., 2017). Antibiotic use also reduces the abundance of Bifidobacterium and Bacteroides, and it delays the development of gut microbiota (Penders et al., 2006; Bokulich et al., 2016; Wampach et al., 2017). Afterward, the gut microbiota develops with age and dietary changes. For example, the original dominant species such as Bifidobacterium decrease with age (Penders et al., 2006; Bokulich et al., 2016). The phylogenetic composition of the infant microbiota increases rapidly after birth, and it evolves toward an adultlike configuration within a 3year period (Yatsunenko et al., 2012; Bokulich et al., 2016). Then, the phylogenetic composition and diversity continue to evolve, and the drastic changes of adolescence greatly impact the development of the microbiota (Kundu et al., 2017). The gut microbiota is relatively stable in adulthood, and more than $60 \%$ of the microbiota, including Bacteroidetes and Actinobacteria, experiences little changes (Faith et al., 2013; Borre et al., 2014). In old age, the diversity of the gut microbiota declines, while the richness of some opportunistic pathogens, including some
Clostridium species, increases (Claesson et al., 2011; Kundu et al., 2017).

The gut microbiota influences the development and maturation of the brain and mind (Diaz Heijtz et al., 2011; Borre et al., 2014; Galland, 2014; Mu et al., 2016; Manderino et al., 2017; Bruce-Keller et al., 2018). Germ-free (GF) animals not only present developmental defects in brain structure, but also show abnormal mental development (Diaz Heijtz et al., 2011; Desbonnet et al., 2014; Ogbonnaya et al., 2015; Hoban et al., 2016; Luczynski et al., 2016; Chen et al., 2017). Both neuroplasticity and myelin plasticity are influenced by the gut microbiota (Ogbonnaya et al., 2015; Hoban et al., 2016). An abnormal gut microbiota can induce brain dysfunction and mental disorders. Risk factors disturbing microbiota growth, such as maternal stress, early infection, antibiotic use, and early adversity, also perturb the development of the brain and mind (O’Mahony et al., 2009; Borre et al., 2014; Gur et al., 2015; Diaz Heijtz, 2016; Lim et al., 2016; Slykerman et al., 2017). Since early postnatal life is the critical stage for the development of the gut-brain, brain, and mind, microbiota abnormality at this time could lead to irreversible damage in the brain and mind (Borre et al., 2014; Bokulich et al., 2016). This could be a part of the reason why early adversity increases susceptibility to mental disorders (O’Mahony et al., 2009, 2017; Mika et al., 2017).

\section{Normal Psychology and Behavior Cannot Exist Without Gut Microbiota}

The gut microbiota plays a significant role in the host's mind and behavior, although this role is usually ignored (Luczynski et al., 2016; Vuong et al., 2017).

First, the gut microbiota regulates pain perception and influences visceral pain response and peripheral pain response. The visceral pain sensitivity of GF mice was shown to be increased and alleviated after transplantation with the feces microbiota of wild-type mice (Luczynski et al., 2017). Pain sensitivity is also augmented after antibiotic treatment or infection, and reduced after supplementation with certain probiotics (Vuong et al., 2017). Myalgic encephalomyelitis/chronic fatigue syndrome patients present abnormal gut microbiota and metabolomics (Armstrong et al., 2017), and their symptoms can be alleviated after treatment with certain probiotics (Rao et al., 2009). Many pain-related disorders, such as functional abdominal pain, migraine, and chronic back pain, are strongly linked with abnormal microbiota (Gawronska et al., 2007; Albert et al., 2013; Dai et al., 2017).

Second, cognitive functions, including learning capacity and memory, are closely related to the gut microbiota (Gareau, 2016; Manderino et al., 2017). Either depriving the commensal microbiota or disrupting the microbiota with antibiotics damages working memory and spatial memory, whereas probiotic administration improves memory (Liang et al., 2015; Ohsawa et al., 2015; Wang et al., 2015; Vuong et al., 2017).

Third, mood and emotion are affected by the gut microbiota (Luczynski et al., 2016; Cowan et al., 2017; Hoban et al., 2017; Vuong et al., 2017). Germ-free animals present abnormal anxiety-like behaviors, which appear to be amenable to microbial 

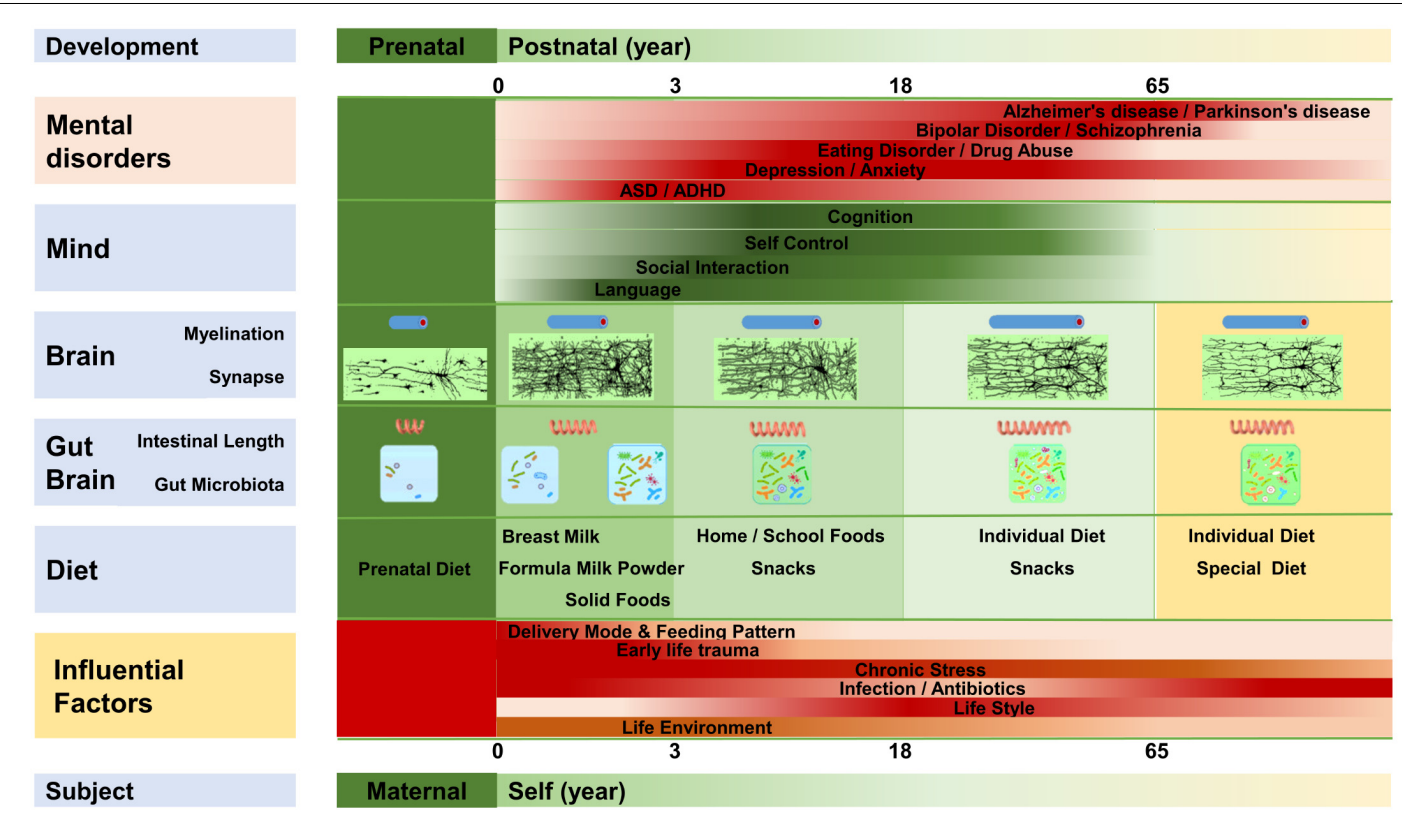

FIGURE 2 | The gut-brain, brain, and mentality develop almost synchronously throughout the lifespan. The gut-brain, brain, and mentality undergo similar developmental patterns; all three are susceptible to several factors that influence the gut microbiota. Myelination, intestinal length, and the gut microbiota develop almost synchronously. Diet plays an important role in the maturation of the gut-brain and brain, and mentality is regulated by the development of the brain and gut-brain. Microbiota disruption at different stages is likely to increase the incidence of different mental disorders.

intervention (Luczynski et al., 2016). Pathogen infection quickly induces sickness behavior, with infected subjects showing fatigue, social avoidance, decreased appetite, and increased anxiety-like behavior (Lyte et al., 2006; Lyte, 2013; De Palma et al., 2014; Gur et al., 2015). Perturbing the gut microbiota using stress or antibiotics also increases anxiety-like and depression-like behaviors (Lurie et al., 2015; Frohlich et al., 2016; Slykerman et al., 2017). Meanwhile, supplementing with certain probiotics, prebiotics, or fermented foods reduces negative behaviors and improves these emotions (Cryan and Dinan, 2012; Steenbergen et al., 2015; McKean et al., 2017; Vuong et al., 2017).

Fourth, temperament and character are closely linked with the gut microbiota-they can even transmit from one subject to another through fecal microbiota transplantation (FMT) under certain conditions (Collins et al., 2013; Kelly et al., 2016; Zheng et al., 2016; Kim H.N. et al., 2017). The transfer of microbiota from high anxiety-like Balb/C mouse strain to low anxiety-like GF NIH Swiss mice has been found to be anxiogenic in the recipient. The same is true of the reverse transplantation: NIH Swiss bacteria transferred into GF Balb/C mice attenuate the recipients' anxious phenotype (Bercik et al., 2011a; Collins et al., 2013). Among toddlers, surgency/extraversion is positively associated with phylogenetic diversity (Christian et al., 2015). Among adults, high neuroticism and low conscientiousness are correlated with the high abundances of Gammaproteobacteria and Proteobacteria, respectively. Meanwhile, high conscientiousness is associated with an increased abundance of some universal butyrateproducing bacteria, including Lachnospiraceae (Kim H.N. et al., 2017).
Fifth, stress management is impacted by the gut microbiota. The gut microbiota is a part of the stress response system (Dinan and Cryan, 2012; Luczynski et al., 2016). Psychological stresses not only activate the neuroendocrine, immune, and nervous systems, but they also destroy mood and disturb the gut microbiota (Gur et al., 2015; Liang et al., 2015; Bharwani et al., 2016). The amygdala, which plays a crucial part in stress-related mood and behavior response as well as in emotion regulation, is remarkably impacted by the gut microbiota (Cowan et al., 2017; Hoban et al., 2017). A healthy microbiota helps the host to cope with stress, whereas an abnormal microbiota reduces the resistance and increases the susceptibility to stress-related disorders (Moloney et al., 2014; Parashar and Udayabanu, 2016; Cowan et al., 2017; Vuong et al., 2017).

Sixth, gut microbiota affects dietary behavior. The dietary patterns of mammals are strongly linked to their gut microbiota, which vary significantly among animals with different dietary compositions (Nishida and Ochman, 2017). A typical example of this is the red panda, in whose gut the metabolism of dietary bamboo depends on the microbiota (Kong et al., 2014). The human appetite is probably modulated by the gut microbiota; some food tastes good possibly because the microbiota requires suitable food to promote its proliferation (van de Wouw et al., 2017). The gut microbiota may also play a vital part in eating disorders, such as anorexia nervosa (Glenny et al., 2017; van de Wouw et al., 2017).

Finally, social interaction and reproductive behavior are strongly linked with the commensal microbiota. A normal gut microbiota is essential for the development of social behavior (Desbonnet et al., 2014). Germ-free mice present more social 
avoidance, while microbiota reconstitution in time improves their social interaction (Montiel-Castro et al., 2013; Desbonnet et al., 2014; Buffington et al., 2016). Social anxiety in response to novel subjects or a novel environment is also related to the gut microbiota (Parashar and Udayabanu, 2016). Mating choices that are dependent on olfaction and reproductive behavior in mammals are impacted by the commensal microbiota (McFallNgai et al., 2013; Stumpf et al., 2013).

\section{Both Mental IIInesses and Neurological Diseases Are Closely Related to Abnormal Microbiota}

Research indicates that mental disorders are likely to be rooted in abnormal gut microbiota, and targeting the microbiota should play a vital role in future therapy (Fond et al., 2015; Liang et al., 2015, 2018b; Ochoa-Reparaz and Kasper, 2018). Depressive disorder is strongly linked to the gut microbiota (Jiang et al., 2015; Liang et al., 2018b), and depressive symptoms can be transmitted from humans to GF or microbiota-depleted rodents through FMT (Kelly et al., 2016; Zheng et al., 2016), while probiotics intervention can alleviate and improve the disorder (Liang et al., 2015; Pirbaglou et al., 2016; Wallace and Milev, 2017). The gut microbiota also plays a crucial part in the etiology of anxiety disorders, such as obsessive compulsive disorder, post-traumatic stress disorder, and panic attacks, while regulating the microbiota brings about therapeutic effects for these disorders (Kantak et al., 2014; Leclercq et al., 2016; Schnorr and Bachner, 2016; Turna et al., 2016). Bipolar disorder is significantly related to microbiota abnormalities (Evans S.J. et al., 2017; Yolken and Dickerson, 2017), and microbiota regulation probably alleviates the disorder (Hamdani et al., 2015; Dickerson et al., 2017). Schizophrenia is related with the dysfunction of microbiota-gut-brain axis (Nemani et al., 2015; RodriguesAmorim et al., 2018; Shen et al., 2018), and improving the gutbrain and immune functions by targeting the microbiota could possibly produce beneficial effects (Davey et al., 2013; Tomasik et al., 2015; Dickerson et al., 2017). Additionally, patients subjected to neurodevelopmental disorders, including autism spectrum disorders (ASD) and attention deficit hyperactivity disorder (ADHD), possess abnormal gut microbiota (Mayer et al., 2014b; Aarts et al., 2017; Strati et al., 2017), while correcting the microbiota abnormalities in a timely manner probably improves the development of the brain and behavior and has remedial effects (Borre et al., 2014; Partty et al., 2015; Kang et al., 2017; Doenyas, 2018; Yang et al., 2018). Neurodegenerative diseases, such as Alzheimer's disease and Parkinson's disease, may also originate from the gut ( $\mathrm{Hu}$ et al., 2016; Liddle, 2018); aberrations first appear in the gut microbiota and gut (Li W. et al., 2017; Mancuso and Santangelo, 2017), with ENS degeneration occurring first and gradually spreading to the CNS, while improving gut-brain function by adjusting the microbiota has remedial effects ( $\mathrm{Hu}$ et al., 2016; Liddle, 2018). The gut microbiota is also involved in the pathophysiology of behavior disorders, including drug addiction and substance abuse, while behavior modifications combined with microbiota regulation may have beneficial effects
(Engen et al., 2015; Vogtmann et al., 2015; Kiraly et al., 2016; Skosnik and Cortes-Briones, 2016). Additionally, the gut microbiota plays a vital role in the pathophysiology of neurobiological diseases, such as multiple sclerosis, hepatic encephalopathy, epilepsy, and migraine (Liang et al., 2012; Sharon et al., 2016; Wu et al., 2016; Dai et al., 2017; van den Hoogen et al., 2017). The prevalence of mental disorders and neurological diseases has been ever increasing, almost in parallel with the changes in the human commensal microbiota. In response to this, therapies targeting the microbiota have gained more and more attention, and attempts to treat these diseases by microbiota intervention using probiotics, prebiotics, and FMT have increased steadily (Cryan and Dinan, 2012; Dinan et al., 2013; Liang et al., 2015; Pirbaglou et al., 2016; He et al., 2017; Kang et al., 2017; Mika et al., 2017; Zhao et al., 2017; Bruce-Keller et al., 2018; Yang et al., 2018). Thus far, researchers have proposed several theories, such as the gut microbiota hypothesis (Liang et al., 2018a,b), the "old friends" hypothesis (Rook and Lowry, 2008), and the leaky gut theory (Smythies and Smythies, 2014), to explain the relationship between the gut microbiota and the abovementioned diseases.

\section{The Gut Microbiota Hypothesis of Brain Disorders}

In 2002, F Jin's lab found that pigs fed with Lactobacillusfermented fodder were more resistant to swine influenza and porcine reproductive and respiratory syndrome when compared with conventional pigs. Their meat was more nutritious and delicious and even their characters were more meek and less aggressive. Since then, the lab has turned its attention to the relationship of the commensal microbiota with behavior and psychology. In 2012, the lab tried to comprehensively elucidate the role that commensal microbiota plays in human mental disorders and neurological diseases (Liang et al., 2012). Then, after a series of experiments, the lab found that anxiety-like behavior, depression-like behavior, and cognitive impairment induced by gastrointestinal disease, a high-fat diet, and antibiotic use were all associated with gut microbiota abnormalities and improved by gut microbiota regulation using specific Lactobacillus strains (Hu et al., 2014, 2015; Luo et al., 2014; Wang et al., 2015). Their next study indicated that the key reason for both acquired and inborn depression was likely to be an abnormal gut microbiota (some of the data were unpublished). In the chronic restraint stress depression model, depressive rats had microbiota that was different from control rats; the traditional antidepressant citalopram alleviated some behavioral and physiological aberrations, but could not recover the microbiota, while the Lactobacillus helveticus NS8 intervention not only improved the behavioral and physiological abnormalities, but also recovered the microbiota (Liang et al., 2015). In the inborn depression model, the Wistar Kyoto (WKY) rats possessed a gut microbiota that was distinct from the control Wistar rats. Chronic restraint stress aggravated the depressivelike symptoms, and Lactobacillus helveticus NS8 supplementation presented the opposite effect with stress; it also alleviated the behavioral, biochemical, and microbiota aberrations as in the case of the acquired depression model. The lab further found 
that aggressive behavior was connected with the microbiota; for example, prisoners with violent tendencies presented higher levels of blood ammonia $\left(\mathrm{NH}_{3}\right)$ (Duan et al., 2015). They also found that ASD, ADHD, and Tourette syndrome were all closely related with gut microbiota abnormalities and could be improved by specific probiotic intervention. This research is still ongoing. Patients diagnosed with Alzheimer's disease and Parkinson's disease have also been found to possess abnormal gut microbiota, and their hypofunction in the brain and gutbrain can be improved by specific probiotic intervention ( $\mathrm{Hu}$ et al., 2016; Li W. et al., 2017). Based on the above research and observations, the lab proposed the gut microbiota hypothesis (Liang et al., 2018a,b). According to this hypothesis, many factors in the modern society, including unhealthy diet, antibiotic use, and life stress, disturb the gut microbiota, and an abnormal microbiota may be a direct risk factor for mental and brain illnesses. Abnormal microbiota and the subsequent dysfunction in the microbiota-gut-brain axis are the main pathophysiology of these disorders, and regulating the microbiota by valid methods, such as probiotics or a healthy diet, will have therapeutic effects.

\section{The "Old Friends" Hypothesis}

The "old friends" hypothesis, or the early immune challenge hypothesis, was proposed by Rook on the basis of Strachan's hygiene hypothesis (Strachan, 1989; Rook and Lowry, 2008; Kramer et al., 2013; Rook, 2013). This theory proposes that the symbiotic relationship between humans and the commensal microbiota has been formed over millions of years of evolution, and that it is evolution dependent and adapted to the huntergatherer life. This microbiota was or used to be humans' "old friends," which include microorganisms and helminths found in pollution-free water, soil, and food. However, in modern society, dramatic changes in health care, lifestyle, and diet have greatly diminished exposure to these friends, which has resulted in abnormalities in immune development. Only through adequate exposure to these "old friends" can naïve dendritic cells (DCs) mature to regulatory dendritic cells (DCreg). In turn, the DCreg induce the maturation of T-lymphocytes into regulatory T-lymphocytes (Treg). The Treg regulate immune tolerance information, which means that these "old friends" and human tissues do not generate an immune response. Regulatory T-lymphocytes also regulate the intensity of immune response by certain biological process, such as the release of interleukin 10 (IL-10), and avoid excessive immune responses that could damage the human body. However, with the lack of the "old friends," the DCs cannot mature, and T-lymphocytes differentiate into effective T-lymphocytes, such as Th1, Th2, and Th17. In this condition, subjects may present immune responses to harmless microorganisms and their own tissues, as in the case of allergies and autoimmune diseases, and they are also likely to present inappropriate and uncontrollable inflammation. Chronic inflammation may be a risk factor for many diseases, including allergies, autoimmune diseases, chronic inflammatory diseases, and mental disorders (Becker, 2007; Rook and Lowry, 2008; Elliott and Weinstock, 2009; Rook et al., 2011, 2017; Bloomfield, 2013; Kramer et al., 2013).

\section{The Leaky Gut Theory}

The human body has two major barriers-the gut barrier and the blood-brain barrier (BBB) - in addition to the placental barrier in pregnant females. The gut barrier regulates the flow of nutrients and signal molecules in the body and prevents the entry of microorganisms, food residue, and harmful substances. The BBB controls the entry and exit of substances in the circulatory system, and its key components are tight junctions (TJs). Thus, the integrity of the barriers is critical for human health (Borre et al., 2014; Kelly et al., 2015). The gut microbiota regulates the development and function of these barriers, for example, influencing the formation of TJs (Braniste et al., 2014). Many factors, such as stress, alcohol use, unhealthy diet, and heavy metal, damage the gut barrier, increase intestinal permeability, and allow biomacromolecules and microorganisms to pass through to the body that could not do so before; this syndrome is called leaky gut (Leclercq et al., 2012; Slyepchenko et al., 2017). The early leaky gut theory emphasizes more on the nutrient absorption and immune function of gut barrier (Fink, 1990), whereas the latest leaky gut theory posits that when the gut barrier is broken, not only bacterial translocation, circulating lipopolysaccharides (LPS) levels, and immunoglobulin (Ig) M and IgA levels increase, but the BBB is also impaired, and cyclic biomacromolecules can even pass through the $\mathrm{BBB}$, reaching the brain and inducing neuroinflammation (McCusker and Kelley, 2013; Smythies and Smythies, 2014; Kelly et al., 2015). These are key contributors to many inflammatory diseases, metabolic diseases, mental disorders, and neurological diseases (de Kort et al., 2011; Fasano, 2012; Smythies and Smythies, 2014; Potgieter et al., 2015; Garcia Bueno et al., 2016; Slyepchenko et al., 2017). Repairing the gut barrier by microbiota regulation is likely to be an effective therapy for these diseases (Ait-Belgnaoui et al., 2012).

In conclusion, human mind and behavior are not only regulated by the brain, but are also probably impacted by the gut-brain. Thus, factors perturbing the gut microbiota also affect the brain and mind simultaneously. Although each of the above theories has a different focus, all of them hold that mental disorders are closely related to abnormal gut microbiota. The "old friends" hypothesis emphasizes the evolution of the microbiota, whereas the leaky gut theory emphasizes on the function of the gut barrier, but both the theories recognize immune dysfunction as the main cause and future therapy target for brain disorders. Both the gut microbiota hypothesis and the leaky gut theory hold that abnormal microbiota injures gut-brain function, thereby, damaging brain function and finally inducing mental and brain disorders. However, the gut microbiota hypothesis puts more emphasis on how the microbiota influences the brain and behavior, which is currently the field of greatest concern in gut-brain psychology.

\section{GUT MICROBIOTA IMPACTS THE BRAIN AND BEHAVIOR THROUGH THE MICROBIOTA-GUT-BRAIN AXIS}

The brain-gut axis is the bidirectional communication between the CNS and the digestive tract (Wood, 2007; 
O'Mahony et al., 2011; Liang et al., 2012). Recent research reminds us to bring gut microbiota into this axis, which is the microbiota-gut-brain axis. As shown in Figure 3, the influences of microbiota overstep the gut and reach the whole body, especially the brain, through the microbiota-gut-brain axis (Cryan and O'Mahony, 2011; Grenham et al., 2011; Collins et al., 2012; Mayer et al., 2014a, 2015; Smith, 2015; Kelly et al., 2017; Cox and Weiner, 2018; Dinan et al., 2018; Liang et al., 2018b). The microbiota-gut-brain axis mainly contains three pathways: the nerve pathway, neuroendocrine pathway, and immune pathway.

\section{Nerve Pathway}

The nerve pathway is the fastest way through which microbiota affects the brain and behavior; it includes neural conduction (Forsythe et al., 2014), neurotransmitter (Wall et al., 2014), neurogenesis (Ogbonnaya et al., 2015), apoptosis, and neurodegeneration (Thion et al., 2017; Westfall et al., 2017).

\section{Neural Conduction}

The oral microbiota impacts not only lower organs, but also the head and brain (Montiel-Castro et al., 2013; Gholizadeh et al., 2016). In certain conditions, the oral microbiota and its metabolites can even directly activate cranial nerves, such as the olfactory nerve and trigeminal nerve, to influence the brain and behavior; they are probably involved in the pathophysiology of neurodegenerative diseases (Garcia-Pena et al., 2017; Marizzoni et al., 2017).

The gut microbiota can affect the brain and behavior through the vagus nerve (Forsythe and Kunze, 2012; Quigley, 2017; Bonaz et al., 2018). The sickness behavior induced by infection is closely related to the vagus nerve. The primary afferents send out the microbial signals first and activate the vagus nerve quickly and then transmit the message to the brain (Forsythe et al., 2014). The gut microbiota recognizes neural signals released by the host and responds appropriately to prompt its own proliferation. They can also respond quite differently to different catecholamines and recognize other neural signals, such as serotonin (5-HT), gamma-aminobutyric acid (GABA), and neuropeptides (Lyte, 2014b; Sudo, 2014; Wall et al., 2014). Infection by pathogens, such as Campylobacter jejuni and Citrobacter amalonaticus, increases anxiety-like behavior, while probiotic supplementation with bacteria, including Lactobacillus rhamnosus and Bifidobacterium longum, reduces anxiety-like and depression-like behaviors. Both the anxiogenic/depressive effect and the anxiolytic/antidepressant effects depend on the vagus nerve, and they are eliminated by vagotomy (Lyte et al., 2006; Bercik et al., 2011b; Bravo et al., 2011; Forsythe and Kunze, 2012; Forsythe et al., 2014).

It is unclear how the sympathetic nervous system works in the communication between the gut and brain, but the research on hypertension has revealed that it is involved in the regulation of the gut barrier function (Taylor and Takemiya, 2017; Yang and Zubcevic, 2017).

\section{Neurotransmitters}

The neurotransmitter content of mammals is regulated not only by their own bodies, but also by their gut microbiota
(Diaz Heijtz et al., 2011; Wall et al., 2014). Gut microbiota can synthesize neurotransmitters directly (Lyte, 2014a; Wall et al., 2014; Mazzoli and Pessione, 2016), and more than 90\% of 5 -HT and $50 \%$ of dopamine (DA) are synthesized in the gut (Sudo, 2014; Yano et al., 2015). Many bacteria, including Bacillus strains and some lactic acid bacteria (LAB) species, synthesize catecholamines and/or acetylcholine (ACh) (Wall et al., 2014). Members of the genera Candida, Streptococcus, Escherichia, and Enterococcus synthesize 5-HT (Holzer and Farzi, 2014). Several coryneform bacteria and many LAB strains are able to produce glutamate (Glu), and both prokaryotes and eukaryotes synthesize GABA through the decarboxylation of Glu by glutamate decarboxylase (Mazzoli and Pessione, 2016).

Gut microbiota regulates the synthesis of neurotransmitters by changing the neurotransmitter-related metabolism pathways (O’Mahony et al., 2014; Mazzoli and Pessione, 2016). Taking 5 -HT as an example, more than $90 \%$ of the body's 5HT is synthesized in the gut by enterochromaffin cells (Margolis et al., 2014). Tryptophan can synthesize 5-HT, and it can also produce kynurenine catalyzed by the largely hepatic-based enzyme tryptophan-2,3-dioxygenase (TDO) or the ubiquitous indoleamine-2,3-dioxygenase (IDO) (O'Mahony et al., 2014). Some indigenous spore-forming microbes can induce the biosynthesis and bioavailability of 5-HT by prompting enterochromaffin cells to upregulate tryptophan hydroxylase 1 expression (Yano et al., 2015; Yang et al., 2017). The gut microbiota also regulates the brain concentration of 5-HT, which is probably implemented by the inhibition of the kynurenine pathway (Desbonnet et al., 2008; Luo et al., 2014; Liang et al., 2015; Kennedy et al., 2017).

The gut microbiota impacts the expression of neurotransmitter-related genes. Many genes linked with neurotransmitters in the striatum of male GF NMRI mice were found to be expressed differently when compared with their specific pathogen-free (SPF) counterparts (Diaz Heijtz et al., 2011). Additionally, the mRNA expression of the NR2B subunit of $N$-methyl-D-aspartate (NMDA) receptors in the central amygdala and the $5-\mathrm{HT}_{1 \mathrm{~A}}$ receptor in the hippocampus of female NMRI mice was reduced when compared with the SPF mice (Neufeld et al., 2011). Moreover, the gene expression of $\mathrm{GABA}_{\mathrm{A}}$ and $\mathrm{GABA}_{\mathrm{B}}$ in several areas of the brain changed after Lactobacillus rhamnosus JB-1 intervention in adult BALB/c mice (Bravo et al., 2011).

\section{Neurogenesis, Apoptosis, and Neurodegeneration}

Adult neurogenesis is influenced by the gut microbiota. The hippocampal neurogenesis of adult GF mice was found to be increased when compared with conventional mice, and postweaning microbial colonization of GF mice did not affect the abnormalities, suggesting that there is a critical window in early life during which microbial colonization influences adult hippocampal neurogenesis (Ogbonnaya et al., 2015). Brain neurogenesis is regulated by the brain-derived neurotrophic factor (BDNF), while the content and gene expression of BDNF are regulated by the gut microbiota. The concentration and gene expression of brain BDNF changed in GF animals and decreased 


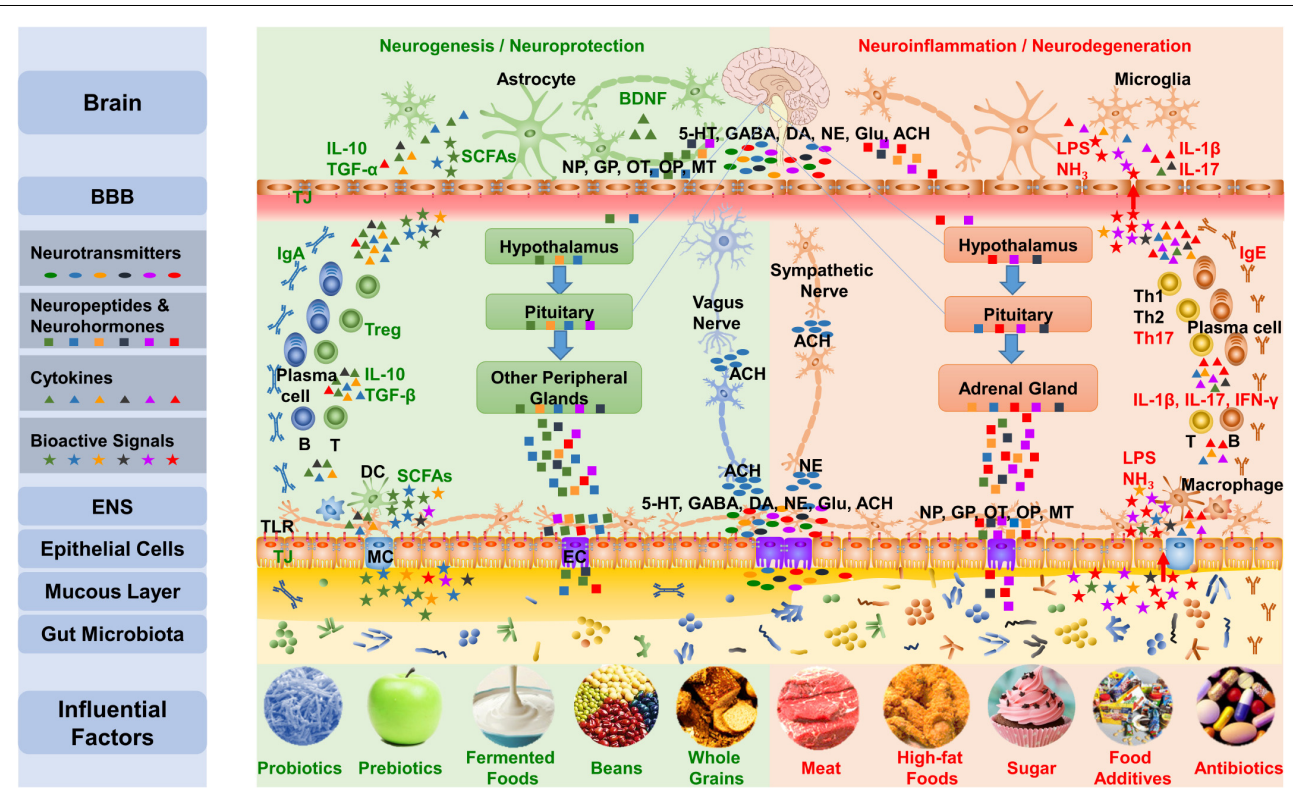

FIGURE 3 | The gut-brain communicates with the brain mainly via three pathways of the microbiota-gut-brain axis. First, the gut microbiota influences the synthesis and secretion of neurotransmitters, including 5-HT, GABA, DA, NE, Glu, and ACh. Gut signals can activate the ENS and primary afferents as well as transmit messages to the brain through the vagus nerve and the sympathetic nervous system. Second, the gut microbiota impacts the concentration and function of neuropeptides that include neuropeptides, gut peptides, OT, and opioid peptides and neurohormones, such as melatonin, communicating with the brain through the neuroendocrine pathway, including the HPA axis and hypothalamus-pituitary-other peripheral glands axis. Third, the gut microbiota regulates the function of TJs and TLRs in the gut barrier and BBB, adjusts the differentiation of lymphocytes, and impacts the brain via the immune pathway. Additionally, the bioactive products of the microbiota also influence the microbiota-gut-brain axis. The five influential factors on the left protect the microbiota and the mucous layer, leading to the production of beneficial substances, such as SCFA, by the microbiota, which results in an anti-inflammatory environment; meanwhile, the five factors on the right are likely to interrupt the normal function of the gut-brain, which can induce mucus loss and microbiota disturbance, leading to the production of harmful substances such as lipopolysaccharide and $\mathrm{NH}_{3}$ and resulting in a pro-inflammatory environment. NP, Neuropeptides; GP, Gut peptides; OP, Opioid peptides; MT, Melatonin; LPS, lipopolysaccharide; MC, M cell; EC, Enteroendocrine cell.

in frail subjects, but increased after probiotic intervention (Sudo et al., 2005; Bercik et al., 2010; Ait-Belgnaoui et al., 2014; Distrutti et al., 2014; Maqsood and Stone, 2016).

Myelination and myelin plasticity are also impacted by the gut microbiota. The absence of microbiota was found to result in hypermyelinated axons in the prefrontal cortex and the overexpression of myelin component genes in a region- and sex-dependent manner. Conventional microbiota colonization following weaning inhibited the overexpression of these genes, but it did not reverse the levels of the proteins they encoded (Hoban et al., 2016). The gut microbiota plays a vital role in diseases characterized by CNS demyelination, such as multiple sclerosis (Lee et al., 2011; Girolamo et al., 2017; van den Hoogen et al., 2017).

The apoptosis of neurons is related to gut microbiota. The programmed cell death in the hypothalamus and some hippocampus areas was found to be increased in neonatal GF mice when compared with conventional mice, which was paralleled by the elevation in the number and density of microglia and the increase of microglia biomarkers in these areas (CastilloRuiz et al., 2018).

Neurodegeneration and its accumulation are influenced by the gut microbiota. Abnormal microbiota or microbial metabolites may influence neurodegeneration through the promotion of amyloid formation by human proteins or by enhancing inflammatory responses to endogenous neuronal amyloids (Friedland and Chapman, 2017; Hoffman et al., 2017; Minter et al., 2017), while microbiota interventions, such as probiotic supplementation, may prevent or even reverse this process (Hu et al., 2016; Westfall et al., 2017).

\section{Endocrine or Humoral Pathway}

The gut is the largest endocrine organ in the human body. It contains more than 20 different kinds of enteroendocrine cells, expresses more than 30 kinds of hormone genes, each with several phenotypes, and secretes more than 100 hormonal peptides (Raybould, 2010; Rehfeld, 2014). The gut microbiota can influence the brain and behavior through the endocrine pathway, directed by the neuroendocrine cells, neuropeptides, and neuroactive substances (Liang et al., 2012; Holzer and Farzi, 2014; Sudo, 2014; Wall et al., 2014).

\section{Neuroendocrine}

The endocrine system also governs the whole body via signaling molecules. The hypothalamus is a higher nervous center for the regulation of viscera and endocrine function; it plays a vital role in the secretion of pituitary hormones and autonomic nervous system activity. The pituitary gland is the most important endocrine gland and the main regulator of homeostasis through hormones. It controls the synthesis of many key hormones 
that regulate metabolism, development, reproduction, and other functions. The hypothalamus, pituitary gland, and peripheral endocrine glands constitute the neuroendocrine system, which facilitates the communication between the brain and gut (Sudo, 2014; Rieder et al., 2017; Cussotto et al., 2018).

The hypothalamic-pituitary-adrenal (HPA) axis is the main pathway of neuroendocrine transmission, and it is a crucial part of the stress response system. The gut microbiota is essential to the development and function of the HPA axis (Liang et al., 2012; Sudo, 2014). The absence of a microbiota induces abnormal development of the HPA axis and only colonization within a critical window will prompt HPA axis maturation (Sudo et al., 2005; Liang et al., 2012; Keightley et al., 2015). Germ-free mice were found to present an enhanced HPA stress response and reduced sensitivity to negative feedback signals when compared with SPF mice (Sudo et al., 2005; Sudo, 2006, 2014). The exaggerated HPA response by GF mice was reversed by reconstitution with Bifidobacterium infantis, but it was exacerbated by mono-colonization with enteropathogenic Escherichia coli. The enhanced HPA response of GF mice was also partly corrected by reconstitution with SPF feces at an early stage, but it was not corrected by any reconstitution performed at a later stage (Sudo et al., 2005; Sudo, 2014). Even if one has an intact microbiota, many factors, such as chronic stress and antibiotic use, can impair the function of the HPA axis, while probiotic intervention improves the function of the HPA axis both in juveniles and adults (Eutamene and Bueno, 2007; Gareau et al., 2007; Liang et al., 2015; Wang et al., 2015).

The gut microbiota also plays an important role in the activity of other peripheral endocrine glands, such as the release of sex hormones and thyroid hormones (Neuman et al., 2015; Cussotto et al., 2018). The gut microbiota regulates estrogen primarily through the secretion of $\beta$-glucuronidase, which can deconjugate estrogen into its active forms (Baker et al., 2017). Testosterone enriches the male microbiota with specific bacteria, including SFB, E. coli, and Shigella-like bacteria, while the transplantation of the male microbiota into females elevates testosterone levels (Markle et al., 2013).

\section{Neuropeptides and Neurohormones}

Neuropeptides are a type of bioactive peptide that are widespread in the nervous system; they include neuropeptide Y (NPY), oxytocin (OT), calcitonin gene-related peptide, vasoactive intestinal peptide, somatostatin, corticotrophin-releasing factor (CRF) and so forth. These neuropeptides serve as messengers of the microbiota-gut-brain axis and are either released by enterocytes to regulate microbiota or secreted by the microbiota to influence the host (Holzer and Farzi, 2014; Lach et al., 2017).

The gut microbiota regulates the concentration and activity of gut peptides/gut hormones, including insulin, glucagon, gastrin, cholecystokinin, and leptin (Berthoud, 2008; Lach et al., 2017; Worthington et al., 2018). For example, insulin sensitivity is regulated by the gut microbiota; microbiota disturbance induces insulin resistance, whereas microbiota regulation alleviates insulin resistance (Bekkering et al., 2013; He and Shi, 2017; Kim Y.A. et al., 2017).
The NPY family mainly consists of NPY, peptide YY (PYY), and pancreatic polypeptide (PP). Neuropeptide $\mathrm{Y}$ is the most abundant neuropeptide in brain, and it is found at all levels of the microbiota-gut-brain axis. Meanwhile, PYY and PP are exclusively expressed by the endocrine cells of the digestive system, but they can pass through the BBB to impact the brain (Holzer et al., 2012). The NPY family plays important roles in regulating energy homeostasis, mood, and stress resilience (Holzer, 2016; Lach et al., 2017). Neuropeptide Y regulates microbiota composition mainly by altering gastrointestinal activity and immunity. In turn, the microbiota recognizes NPYs, impacts their synthesis and secretion, and ultimately influences the brain and behavior (Holzer et al., 2012; Holzer and Farzi, 2014; Holzer, 2016; Lach et al., 2017).

Oxytocin plays an important part in many activities, such as parturition, lactation, social interaction, and stress response (Fineberg and Ross, 2017). The synthesis and release of OT are probably impacted by the gut microbiota. Microbiota depletion from weaning by antibiotics induces abnormal behaviors and cognitive impairment, and reduces OT mRNA levels in the hypothalamus (Desbonnet et al., 2015). Maternal high-fat diet (MHFD) offspring exhibit social deficits, gut microbiota abnormalities, and OT immunoreactive neuron reduction in the hypothalamus; these abnormalities can be prevented by cohousing with the offspring of mothers on a regular diet or Lactobacillus reuteri treatment, and can be transmitted to GF mice after microbiota colonization from MHFD mice (Buffington et al., 2016).

Opioid peptides are one kind of neurohormones that widely exist in the brain and peripheral organs (Terenius, 2000; Bodnar, 2016). The endogenous opioid system plays a crucial role in many different kinds of human activities, of which pain and analgesia, tolerance, and dependence are of the greatest concern (Akbarali and Dewey, 2017; Bodnar, 2017; Hearing et al., 2018). Although it is unclear how the endogenous opioid system is involved in the microbiota-gut-brain axis, opioids significantly alter the composition of the gut microbiota, while the microbiota possibly plays important roles in behavioral responses to opioids, including the development of tolerance to its pain-relieving effects (Meng et al., 2015; Banerjee et al., 2016; Kiraly et al., 2016; Lazaro et al., 2016; Skosnik and Cortes-Briones, 2016; Acharya et al., 2017; Akbarali and Dewey, 2017; Wang and Roy, 2017).

Furthermore, circadian rhythms are fundamental properties of mammals, and the microbiota is also regulated by the host's circadian clock (Paulose and Cassone, 2016; Zhao and Zhang, 2017). Melatonin is a neurohormone secreted by the pineal gland that plays a vital role in the regulation of the circadian rhythm. Host circadian rhythms are influenced by bacterial signaling via the immune system, and the gut bacteria are sensitive to melatonin (Paulose et al., 2016; Thaiss et al., 2017). For example, melatonin specifically increases the magnitude of swarming in cultures of Enterobacter aerogenes in a dose- and temperaturedependent manner (Paulose and Cassone, 2016).

\section{Neuroactive Substances}

The neuroactive substances generated during gut microbiota metabolism, including fatty acids, neural signals, and polyamines, 
also impact the brain and behavior (Forsythe and Kunze, 2012; Kibe et al., 2014; Wall et al., 2014).

The gut microbiota produces short-chain fatty acids (SCFAs), such as acetic acid, propionic acid, and butyric acid, mostly from the degradation of fibers (Koh et al., 2016). The SCFAs are recognized by the receptors in enterocyte and enteroendocrine cells; thereby, SFCAs further affect the nervous and immune systems (Wall et al., 2014; Koh et al., 2016). In addition, they can pass the $\mathrm{BBB}$ to regulate brain development and neurotransmitter synthesis, thereby impacting the maturation and function of microglia (Erny et al., 2015). Polyunsaturated fatty acids (PUFAs), including arachidonic acid and docosatetraenoic acid, are important constituents of the brain, and they affect brain growth and neurotransmission. PUFAs regulate the gut microbiota, while microbiota, such as Bifidobacterium breve NCIMB702258, impacts the brain PUFA content (Wall et al., 2012; Robertson et al., 2017). Conjugated linoleic acid (CLA) can pass through the $\mathrm{BBB}$ and be metabolized in the brain, thereby influencing the brain and behavior, while certain bacteria, including some strains of Lactobacillus and Bifidobacterium, synthesize CLA (Wall et al., 2014).

The gut microbiota also produces other substances, such as amines, phenols, $\mathrm{NH}_{3}$, indole, indole derivatives, and sulfureted hydrogen, from the metabolism of proteins and amine acids (Hamer et al., 2012; Pimentel et al., 2013; Agus et al., 2018). Take $\mathrm{NH}_{3}$ as an example; most of the ammonia in the blood is produced in the gut by the decomposition of urea by gut bacteria, such as Helicobacter pylori. The accumulation of $\mathrm{NH}_{3}$ in the blood damages astrocyte cells and disturbs neurotransmitters, including Glu and GABA. Hyperammonemia is one of the important risk factors of neurological diseases, such as hepatic encephalopathy and autism (Albrecht, 2007; Liang et al., 2012; Wang et al., 2012).

\section{Immune Pathway}

The gut is also the biggest immune organ of the human body. Its internal surface area is about 200 square meters, and it forms a barrier separating the intestinal tissue from the outside. Gut mucosal immunity is one of the most important parts of the innate immune system, and the immune cells in gut-associated lymphatic tissue (GALT) account for about 70 to $80 \%$ of the total immunologically active cells (Tlaskalova-Hogenova et al., 2005). The immune system plays a crucial role in the symbiotic relationship with commensal microbiota; it has coevolved with the microbiota for millions of years, and it cannot mature without normal microbial colonization. The absence of the microbiota leads to significant immune deficiency (Gensollen et al., 2016). The gut microbiota regulates the development and function of innate and adaptive immunity and influences neuroimmunity and inflammation to change the brain and behavior (Freestone et al., 2008; Lee and Mazmanian, 2010; Liang et al., 2012; Lyte, 2014a; Neuman et al., 2015; Levy et al., 2017).

\section{Innate Immunity}

The maturation and function of the innate immunity depend on the gut microbiota. The gut microbiota affects the development and function and the immune barrier, and it regulates the expression of pattern recognition receptors (PRRs) and the development of innate immune cells (Tlaskalova-Hogenova et al., 2005; Thaiss et al., 2014).

The development and function of the gut barrier and BBB are dependent on the gut microbiota. Barrier deficiency induced by microbiota absence or dysbiosis increases susceptibility to various diseases, including allergies and inflammatory bowel disease (Geuking et al., 2014; Gensollen et al., 2016). The absence of a microbiota downregulates the expression of TJs, increases BBB permeability, and can even induce leaky brain (Braniste et al., 2014; Kelly et al., 2015; Hu et al., 2016). This abnormality could last from the fetal stage to adulthood. Supplementing with specific probiotics has been found to increase the expression of TJs and reduce BBB permeability (Bien-Ly and Watts, 2014; Braniste et al., 2014). Abnormal microbiota not only leads to leaky gut and leaky brain, but it is also likely to induce stressrelated disorders and neurodegenerative diseases (Kelly et al., 2015; Hoffman et al., 2017).

The gut microbiota impacts the expression and signal transmission of PRRs (Thaiss et al., 2014). Many PRRs, such as toll-like receptors (TLRs) and nucleotide oligomerization domain-like receptors (NLRs), are expressed in enterocytes; they recognize microbiota material and stimulate a series of immune responses to eliminate or inactivate the pathogen, but tolerate the commensal and harmless material (Artis, 2008; Thaiss et al., 2014). For example, TLR-4 can recognize bacterial LPS and induce immune responses, and the overactivation of TLR-4 in the periphery may play an important part in stress-related mental illnesses and substance abuse (Garcia Bueno et al., 2016). When the gut barrier is impaired, circulating LPS increase and enter into other organs including the brain, resulting in various physiological and/or behavioral symptoms (Rudzki and Szulc, 2018). Lipopolysaccharide injection is a common immune activation model, and systemic LPS treatment might be used as an in vivo model for neuroinflammation or neurodegeneration (Noh et al., 2014).

The gut microbiota regulates the differentiation and development of innate immunocytes. Gut innate immunocytes, such as macrophages, innate lymphoid cells, and DC, differentiate and mature following normal microbial colonization (Tlaskalova-Hogenova et al., 2005; Thaiss et al., 2014). Microglia are a kind of highly specialized tissue macrophages in the CNS; they account for $20 \%$ of the total neuroglia, and they play a vital role in immune surveillance and homeostasis of the CNS (Prinz et al., 2014). The gut microbiota regulates the maturation and function of neuroglia from prenatal stages in a sex- and time-dependent manner (Erny et al., 2015; Matcovitch-Natan et al., 2016; Thion et al., 2017). The absence of a microbiota, microbiota disturbance, and limited microbiota complexity all induce microglia deficiency, leading to impaired innate immune responses, while recolonization of a normal microbiota partly recovers microglia features in an SCFA-dependent manner (Erny et al., 2015).

\section{Adaptive Immunity}

Adaptive immunity develops and matures during exposure to and through combat with the microbiota. The gut microbiota 
regulates the differentiation and function of lymphocytes, influencing the synthesis and release of antibodies (Artis, 2008; Lee and Mazmanian, 2010). The immune system can distinguish beneficial bacteria and pathogens and tolerate self-components and harmless material only if it is exposed to the microbiota in early life (Rook and Lowry, 2008; Knoop et al., 2017).

The differentiation and function of T-lymphocytes are regulated by the gut microbiota (Knoop et al., 2017). The gut microbiota regulates whether naive $\mathrm{CD} 4+\mathrm{T}$-lymphocytes (Tnai) differentiate into effective T-lymphocytes to produce a pro-inflammatory response or into Treg to generate antiinflammatory effects (Honda and Littman, 2016). In conditions that include microbial absence and microbiota abnormality, SFB prompt the Tnai to differentiate into Th17 and induce autoimmune diseases, such as multiple sclerosis (Lee and Mazmanian, 2010; Lee et al., 2011). Even maternal immune activation facilitates the differentiation of Th17, increasing the incidence of neurodevelopmental diseases in the offspring (Kim S. et al., 2017), while probiotic interventions, including Lactobacillus helveticus and Bacteroides fragilis, induce the differentiation of Treg and the release of IL-10, thereby improving immunity (Ochoa-Reparaz et al., 2009; Ohland et al., 2013; Liang et al., 2015).

The gut microbiota also regulates the differentiation and development of B-lymphocytes, influencing the synthesis and secretion of Ig (Honda and Littman, 2016). Even microbiota metabolites, such as SCFA, influence the differentiation by changing the expression of related genes (Hansson et al., 2011; Kim et al., 2016; McCoy et al., 2017). Immunoglobulin A is a vital component of non-inflammatory immune protection, and it also influences the composition and diversity of the microbiota, while the commensal microbiota regulates the synthesis and release of IgA (Dolle et al., 2016; Honda and Littman, 2016). Commensal microbiota inhibits the secretion of IgE, but promotes the secretion of IgG (McCoy et al., 2017). Absence of a microbiota decreases the content of IgA and IgG1, while increasing the content of IgE, thereby increasing the susceptibility to various diseases (Gensollen et al., 2016).

\section{Inflammation}

The gut microbiota not only impacts the differentiation and maturation of immune cells, but it also regulates the immune response. A healthy microbiota prompts immunocytes to release moderate anti-inflammatory cytokines, such as IL-10, transforming growth factor beta (TGF- $\beta$ ), and TGF- $\alpha$, and to secrete moderate pro-inflammatory cytokines, such as IL$1 \beta$, IL-17, IFN- $\gamma$, and tumor necrosis factor alpha (TNF- $\alpha$ ), facilitating the appropriate immune responses (Rook and Lowry, 2008; Rothhammer et al., 2018). However, abnormal microbiota induces an imbalance between anti-inflammation and pro-inflammation, impairs the functions of immune tolerance and immune surveillance, and may even result in chronic inflammation. Chronic inflammation is a key factor in autoimmune diseases and inflammatory diseases, and it can also be found in obese and aging subjects (Rook and Lowry, 2008; Lee and Mazmanian, 2010; Liang et al., 2012).
Abnormal microbiota not only leads to peripheral inflammation, but also probably results in neuroinflammation; it could further damage the BBB integrity, inducing neuron apoptosis, microglia dysfunction, and neurodegeneration, finally causing memory decline, abnormal behavior, and dyskinesia, which are omens of many mental disorders and brain diseases (Daulatzai, 2014; Castanon et al., 2015; Maranduba et al., 2015; Rea et al., 2016; Sampson et al., 2016). Meanwhile, the reconstitution of a healthy microbiota using probiotics or prebiotics is likely to improve immunity and alleviate the brain dysfunction and cognitive and behavioral abnormalities (Dinan et al., 2013; Daulatzai, 2014; Liang et al., 2015; Liu et al., 2015).

\section{Information Integration in the Microbiota-Gut-Brain Axis}

The interplay among the nervous system, endocrine system, and immune system makes the brain and gut-brain multifunctional organs; both the brain and gut-brain orchestrate our metabolism, immunity, and endocrine function. Beyond the comprehensive analysis of the brain and gut-brain, the interaction also appears in information transmission via neuronal, endocrine, and immune pathways. The influence of the gut microbiota on the brain and behavior is the result of this interplay.

The gut-brain integrates the endogenous and exogenous signals of the neuronal, endocrine, and immune pathways, and enterocytes recognize and respond to messages from more than two pathways. For example, the enterochromaffin cell is a crucial endocrine and information conversion cell located on the surface layer of the gut that expresses various receptors, such as 5-HT, norepinephrine, and CRF receptors. When stimulated, it secretes active substances, such as 5 -HT and signal peptides, which activate the afferent nerve endings and transmit the message upward through the vagus nerves (Rhee et al., 2009). The synthesis and release of 5-HT by enterochromaffin cells are impacted by the gut microbiota (Yano et al., 2015). Gut epithelial cells and lymphocytes also recognize microbiota signals by PRRs and secrete substances, including cytokines, 5-HT, and CRF, to activate immune, neuronal, and endocrine pathways (Artis, 2008; Rhee et al., 2009).

The three pathways of the microbiota-gut-brain axis interact with each other. For example, the increase of pro-inflammatory cytokines in inflammation enhances the activity of IDO and promotes the metabolization of tryptophan into kynurenine. Meanwhile, under stress condition, the increased glucocorticoid levels heighten TDO activity and induce the kynurenine pathway. Both conditions inhibit 5-HT synthesis by reducing available tryptophan, changing behaviors, and even possibly leading to depression (Le Floc'h et al., 2011; Baganz and Blakely, 2013; O’Mahony et al., 2014).

In conclusion, the microbiota-gut-brain axis is a bidirectional information communication network. The brain governs other organs and regulates the survival and proliferation of the microbiota, while the microbiota impacts the brain and behavior through neuronal, endocrine, and immune pathways. The emotional, behavioral, and brain changes under stress 
affect the microbiota through the microbiota-gut-brain axis. Hosts can also consciously change their diet to induce the proliferation of beneficial microorganisms in order to improve microbiota-gut-brain axis function and promote health and wellbeing.

\section{TARGETING MICROBIOTA-GUT-BRAIN AXIS TO PROMOTE BRAIN AND MENTAL HEALTH}

It is foreseeable that the establishment of gut-brain psychology will bring tremendous changes to psychology and related disciplines. Gut-brain psychology will contribute to the development of general psychology, aiding research on subjects, such as character, memory, and behavior. It may also help illuminate controversial areas, including the study of unconsciousness. However, its more crucial influence is likely to be in clinical application, for example, in regulating the brain and behavior through gut microbiota intervention. The related research and applications will undoubtedly exert a far-reaching impact on many fields, including psychology, medication, food, and environment (Barratt et al., 2017; Leulier et al., 2017; McKenzie et al., 2017).

There are mainly seven recognized microbiota interventions: the GF technique, pathogen infection, antibiotics, FMT, probiotics, prebiotics, and diet (Cryan and Dinan, 2012; Aroniadis and Brandt, 2013; Cammarota et al., 2014; Liu et al., 2015); all of the methods have shown great potential in regulating mind and behavior (Cryan and Dinan, 2012; Bercik and Collins, 2014; Desbonnet et al., 2014; Liu et al., 2015; Evrensel and Ceylan, 2016; Liang et al., 2018b). Among these methods, the first two are only feasible in experimental animals, the third one is usually used in anti-infection, and the last four are all promising in microbiota improvement.

Fecal microbiota transplantation is the process of transplanting feces from a healthy donor to the receiver's gut in order to recover the impaired intestinal flora. It has been effectively used in the treatment of various diseases including recurrent Clostridium difficile infection and inflammatory bowel disease, and its improved model-selective microbiota transplantation- has been put to use (Aroniadis and Brandt, 2013; Zhang et al., 2018). Remolding the gut microbiota through FMT not only recovers digestive function, but also improves the brain and behavior (Evrensel and Ceylan, 2016). Latest research indicates that FMT can be used in the treatment of many brain diseases, such as ASD (Kang et al., 2017), Tourette Syndrome (Zhao et al., 2017), and epilepsy (He et al., 2017).

Probiotics, such as Lactobacillus and Bifidobacterium, are important components of the gut microbiota, and their related products are widely used in current medications (Kaur et al., 2009; Bested et al., 2013a,b; Sanchez et al., 2017). Dinan et al. (2013) coined the word "psychobiotics" to emphasize on the potential of some probiotics in mental disorder therapy. Animal and clinical studies have identified some psychobiotics that present good antidepressant, anti-anxiety, and/or anti-autism effects. These psychobiotics are likely to work through the regulation of gut microbiota and the improvement of the microbiota-gut-brain axis (Desbonnet et al., 2010; Liang et al., 2015; Mi et al., 2015; Steenbergen et al., 2015; Akkasheh et al., 2016; Pirbaglou et al., 2016; Wallace and Milev, 2017).

Prebiotics mainly include oligosaccharides, unsaturated fatty acids, dietary fibers, and polyphenols (Vyas and Ranganathan, 2012; Liu et al., 2015; Cerdo et al., 2017; Gibson et al., 2017). Studies have found that prebiotics, such as omega-3 fatty acids and oligosaccharides, change the gut microbiota improving the microbiota-gut-brain axis function and symptoms of mental illness subjects (Liu et al., 2015; Burokas et al., 2017; Evans S. et al., 2017; Mika et al., 2017; Robertson et al., 2017). A diet rich in dietary fibers increases gut microbiota diversity, improves the gut barrier, regulates glycometabolism by improving glucose control and insulin sensitivity, modulates lipid metabolism by reducing low-density lipoprotein and cholesterol content, and promotes gut-brain health (Bourassa et al., 2016; Gazzaniga and Kasper, 2016; Koh et al., 2016; Cooper et al., 2017; Gong et al., 2018).

Traditional fermented foods, such as yogurt, natto, and pickles, also regulate the gut microbiota and promote gutbrain health. Diets rich in fermented food, dietary fibers, and unsaturated fatty acids, such as the Mediterranean diet and Japanese diet, also facilitate the proliferation of beneficial microorganisms and improve health and wellbeing (Quirk et al., 2013; Gutierrez-Diaz et al., 2016; Sandhu et al., 2017). The healthy diet probably promotes the function of the microbiotagut-brain axis and leads to improvements in health and well-being, whereas unhealthy diets including high-fat diets, high-refined carbohydrate diets, and low-MACs diets damage mood and memory (Bereswill et al., 2014; Hu et al., 2014, 2015; Marques et al., 2014; Murphy et al., 2014; Wang et al., 2015; Sandhu et al., 2017). Allen et al. (2017) proposed nutritional psychology to connect the microbiota-gut-brain axis with psychology. In our opinion, nutritional psychology posits that mind and behavior are closely related to the gut microbiota. Food is the most influential factor for the gut microbiota, exerting its influence throughout the whole lifetime. An individual's diet shapes his or her gut microbiota and regulates gut-brain function. Through the microbiota-gut-brain axis, different types of microbiota exert different influences on the brain and behavior. A healthy diet contributes to a healthy gut microbiota and gut-brain and promotes brain and mental health through the microbiota-gut-brain axis. Meanwhile, an unhealthy diet disturbs the gut microbiota and damages gut-brain function, induces microbiota-gutbrain axis dysfunction and finally harms the brain and wellbeing.

Dietotherapy is the improvement of health through dietary adjustment. It has been used as an adjuvant treatment for mental disorder therapy for a long time, but it is often doubted for its controversial mechanisms (Lakhan and Vieira, 2008; Lang et al., 2015; Owen and Corfe, 2017). Traditional research has usually focused on the function of certain foods or certain 
nutrients, such as omega-3 and omega- 6 fatty acids (Lakhan and Vieira, 2008; Evans S. et al., 2017; Robertson et al., 2017). Recently, studies have started to pay more attention to the relationship between diet quality and mental illness. Because human beings do not eat just one kind of food, the deficit of one food can have as significant an effect as the excess of another food (Quirk et al., 2013; Lang et al., 2015). Sarris et al. (2015) proposed nutritional psychiatry; they believed that food would play an important part in the prevention and therapy of mental disorders in the future (Sarris et al., 2015; Zepf et al., 2016; Jacka, 2017). With the development of gut-brain psychology and nutritional psychology as the mechanisms of mental disorders and with the role of food in these disorders being clarified, nutritional psychiatry will enter a new stage. Moreover, combining dietotherapy with other interventions, including drug treatment, psychotherapy, and exercise, has shown some good effects in mental therapy (Clarke et al., 2014; Schnorr and Bachner, 2016; Bambling et al., 2017).

\section{CONCLUSION AND OUTLOOK}

Over hundreds of years, psychology has progressed remarkably. Psychologists have intensively studied various mental processes and phenomena, and numerous subdisciplines have sprung up in this process. However, mental disorders remain a problem, and relevant research and therapies lag behind those of other diseases.

This lag reminds us that most psychological research has omitted the fact that the human being is a superorganism. The main part of the superorganism is the microbiota, which accounts for more than $90 \%$ of the total genes and total cell numbers in the human body. These microorganisms have coexisted with humans for millions of years and play a vital part in the maturation and function of most human organs. However, since modernization, the commensal microbiota has been continually altered, and in some cases, it has been lost following the dramatic changes in diet, lifestyle, and medication. These alterations have paralleled the transformation of disease patterns in modern society.

The gut microbiota is the most important part of the commensal microbiota, and it can work together with the gut as a whole to respond to endogenous and exogenous signals. The combination of the gut and gut microbiota is called the gut-brain because its activity is partly independent of the brain. The gut microbiota not only regulates the composition and function of the gut-brain, but it also influences the brain and behavior. The abnormal development of the gut microbiota could lead to neurodevelopmental disorders. Various aspects of normal psychology, such as pain perception, emotion, cognition, character, stress management, and social behavior, are impacted by the gut microbiota. Microbiota disturbance can be induced by many factors, including stress, antibiotics, and unhealthy diet, and it could be a direct cause of mental illnesses. Abnormal microbiota is undoubtedly involved in the etiology and pathophysiology of mental disorders, behavioral problems, and neurological diseases, and it will probably be an effective target of future therapy. This viewpoint is strongly supported by the gut microbiota hypothesis, the "old friend" hypothesis, and the leaky gut theory.

The gut-brain is not just a digestive organ but also a neurological, endocrine, and immune organ. The gut microbiota conducts bidirectional information communication with the brain through the microbiota-gut-brain axis; it impacts the host brain and behavior and is also impacted by the host. The microbiota-gut-brain axis mainly consists of the nervous pathway, endocrine pathway, and immune pathway. The nervous pathway mainly operates through neural conductions, neurotransmitters, and through the regulation of neurogenesis, neural apoptosis, and neurodegeneration. The endocrine pathway mainly operates through the neuroendocrine system, neurohormones, and neural active substances. The immune pathway mainly operates through the regulation of innate and adaptive immunity and the peripheral and neural inflammation. Messages transmitted along the microbiota-gutbrain axis are integrated in the brain, the gut-brain, and the three pathways.

The establishment of gut-brain psychology will have a profound influence on psychology and related disciplines. Unlike other psychology subdisciplines, gut-brain psychology will not only promote the progress of fundamental research, but it will also lead to tremendous changes in practical applications. Targeting the microbiota-gut-brain axis to improve brain and behavior will be a research hotspot in neuroscience, psychology, and psychiatry. Improving the gut microbiota through FMT, probiotics, prebiotics, healthy diet, and/or healthy lifestyle to regulate microbiota-gutbrain axis function and promote mental health will be a promising field in the future. Patients suffering from mental disorders or neurological diseases will get help from one or a combination of these interventions. Healthy persons will promote their cognition and resilience from these methods and reduce mental and brain damage by decreasing microbiota disturbances.

\section{AUTHOR CONTRIBUTIONS}

All the authors listed have contributed to the work. SL conceived the main premises and relationships that are the focus of this review, designed the structure of the paper, wrote the paper, and designed the figures of the paper. FJ conceived the main premises and relationships that are the focus of this review, identified the theoretical relevance of the paper, and edited the final version of the paper. XW offered help in writing the review. All the authors read and approved the final manuscript.

\section{ACKNOWLEDGMENTS}

The study was granted by NS Bio Japan. We thank LetPub for providing linguistic assistance during the preparation of this manuscript. 


\section{REFERENCES}

Aarts, E., Ederveen, T. H. A., Naaijen, J., Zwiers, M. P., Boekhorst, J., Timmerman, H. M., et al. (2017). Gut microbiome in ADHD and its relation to neural reward anticipation. PLoS One 12:e0183509. doi: 10.1371/journal.pone.0183509

Acharya, C., Betrapally, N. S., Gillevet, P. M., Sterling, R. K., Akbarali, H., White, M. B., et al. (2017). Chronic opioid use is associated with altered gut microbiota and predicts readmissions in patients with cirrhosis. Aliment. Pharmacol. Ther. 45, 319-331. doi: 10.1111/apt.13858

Agus, A., Planchais, J., and Sokol, H. (2018). Gut microbiota regulation of tryptophan metabolism in health and disease. Cell Host Microbe 23, 716-724. doi: 10.1016/j.chom.2018.05.003

Ait-Belgnaoui, A., Colom, A., Braniste, V., Ramalho, L., Marrot, A., Cartier, C., et al. (2014). Probiotic gut effect prevents the chronic psychological stressinduced brain activity abnormality in mice. Neurogastroenterol. Motil. 26, 510-520. doi: 10.1111/nmo.12295

Ait-Belgnaoui, A., Durand, H., Cartier, C., Chaumaz, G., Eutamene, H., Ferrier, L., et al. (2012). Prevention of gut leakiness by a probiotic treatment leads to attenuated HPA response to an acute psychological stress in rats. Psychoneuroendocrinology 37, 1885-1895. doi: 10.1016/j.psyneuen.2012.03.024

Akbarali, H. I., and Dewey, W. L. (2017). The gut-brain interaction in opioid tolerance. Curr. Opin. Pharmacol. 37, 126-130. doi: 10.1016/j.coph.2017.10.012

Akkasheh, G., Kashani-Poor, Z., Tajabadi-Ebrahimi, M., Jafari, P., Akbari, H., Taghizadeh, M., et al. (2016). Clinical and metabolic response to probiotic administration in patients with major depressive disorder: a randomized, double-blind, placebo-controlled trial. Nutrition 32, 315-320. doi: 10.1016/j. nut.2015.09.003

Albert, H. B., Sorensen, J. S., Christensen, B. S., and Manniche, C. (2013). Antibiotic treatment in patients with chronic low back pain and vertebral bone edema (Modic type 1 changes): a double-blind randomized clinical controlled trial of efficacy. Eur. Spine J. 22, 697-707. doi: 10.1007/s00586-013-2675-y

Albrecht, J. (2007). “Ammonia toxicity in the central nervous system," in Handbook of Neurochemistry and Molecular Neurobiology, ed. A. Lajtha (New York, NY: Plenum Press), 261-276.

Allen, A. P., Dinan, T. G., Clarke, G., and Cryan, J. F. (2017). A psychology of the human brain-gut-microbiome axis. Soc. Pers. Psychol. Compass 11:e12309. doi: $10.1111 / \mathrm{spc} 3.12309$

Armelagos, G. J. (2009). "The paleolithic disease-scape, the hygiene hypothesis, and the second epidemiological transition," in The Hygiene Hypothesis and Darwinian Medicine, ed. G. A. W. Rook (Berlin: Springer Science \& Business Media), 29-43.

Armelagos, G. J., Brown, P. J., and Turner, B. (2005). Evolutionary, historical and political economic perspectives on health and disease. Soc. Sci. Med. 61, 755-765. doi: 10.1016/j.socscimed.2004.08.066

Armstrong, C. W., McGregor, N. R., Lewis, D. P., Butt, H. L., and Gooley, P. R. (2017). The association of fecal microbiota and fecal, blood serum and urine metabolites in myalgic encephalomyelitis/chronic fatigue syndrome. Metabolomics 13:8. doi: 10.1007/s11306-016-1145-z

Aroniadis, O. C., and Brandt, L. J. (2013). Fecal microbiota transplantation: past, present and future. Curr. Opin. Gastroenterol. 29, 79-84. doi: 10.1097/MOG. $0 \mathrm{~b} 013 \mathrm{e} 32835 \mathrm{a} 4 \mathrm{~b} 3 \mathrm{e}$

Artis, D. (2008). Epithelial-cell recognition of commensal bacteria and maintenance of immune homeostasis in the gut. Nat. Rev. Immunol. 8, 411-420. doi: 10.1038/nri2316

Backhed, F. (2010). 99th dahlem conference on infection, inflammation and chronic inflammatory disorders: the normal gut microbiota in health and disease. Clin. Exp. Immunol. 160, 80-84. doi: 10.1111/j.1365-2249.2010.04123.x

Baganz, N. L., and Blakely, R. D. (2013). A dialogue between the immune system and brain, spoken in the language of serotonin. ACS Chem. Neurosci. 4, 48-63. doi: $10.1021 / \mathrm{cn} 300186 \mathrm{~b}$

Baker, J. M., Al-Nakkash, L., and Herbst-Kralovetz, M. M. (2017). Estrogen-gut microbiome axis: physiological and clinical implications. Maturitas 103, 45-53. doi: 10.1016/j.maturitas.2017.06.025

Bambling, M., Edwards, S. C., Hall, S., and Vitetta, L. (2017). A combination of probiotics and magnesium orotate attenuate depression in a small SSRI resistant cohort: an intestinal anti-inflammatory response is suggested. Inflammopharmacology 25, 271-274. doi: 10.1007/s10787-0170311-x
Banerjee, S., Sindberg, G., Wang, F., Meng, J., Sharma, U., Zhang, L., et al. (2016). Opioid-induced gut microbial disruption and bile dysregulation leads to gut barrier compromise and sustained systemic inflammation. Mucosal Immunol. 9, 1418-1428. doi: 10.1038/mi.2016.9

Barratt, M. J., Lebrilla, C., Shapiro, H. Y., and Gordon, J. I. (2017). The gut microbiota, food science, and human nutrition: a timely marriage. Cell Host Microbe 22, 134-141. doi: 10.1016/j.chom.2017.07.006

Becker, K. (2007). Autism, asthma, inflammation, and the hygiene hypothesis. Med. Hypotheses 69, 731-740. doi: 10.1016/j.mehy.2007.02.019

Bekkering, P., Jafri, I., van Overveld, F. J., and Rijkers, G. T. (2013). The intricate association between gut microbiota and development of type 1, type 2 and type 3 diabetes. Expert Rev. Clin. Immunol. 9, 1031-1041. doi: 10.1586/1744666X. 2013.848793

Bercik, P., and Collins, S. M. (2014). The effects of inflammation, infection and antibiotics on the microbiota-gut-brain axis. Adv. Exp. Med. Biol. 817, 279-289. doi: 10.1007/978-1-4939-0897-4_13

Bercik, P., Denou, E., Collins, J., Jackson, W., Lu, J., Jury, J., et al. (2011a). The intestinal microbiota affect central levels of brain-derived neurotropic factor and behavior in mice. Gastroenterology 141, 599-609. doi: 10.1053/j.gastro. 2011.04.052

Bercik, P., Park, A. J., Sinclair, D., Khoshdel, A., Lu, J., Huang, X., et al. (2011b). The anxiolytic effect of Bifidobacterium longum NCC3001 involves vagal pathways for gut-brain communication. Neurogastroenterol. Motil. 23, 1132-1139. doi: 10.1111/j.1365-2982.2011.01796.x

Bercik, P., Verdu, E. F., Foster, J. A., Macri, J., Potter, M., Huang, X. X., et al. (2010). Chronic gastrointestinal inflammation induces anxiety-like behavior and alters central nervous system biochemistry in mice. Gastroenterology 139, 2102.e1-2112.e1. doi: 10.1053/j.gastro.2010.06.063

Bereswill, S., Pyndt Jørgensen, B., Hansen, J. T., Krych, L., Larsen, C., Klein, A. B., et al. (2014). A possible link between food and mood: dietary impact on gut microbiota and behavior in BALB/c mice. PLoS One 9:e103398. doi: 10.1371/ journal.pone.0103398

Berthoud, H. R. (2008). Vagal and hormonal gut-brain communication: from satiation to satisfaction. Neurogastroenterol. Motil. 20(Suppl. 1), 64-72. doi: 10.1111/j.1365-2982.2008.01104.x

Bested, A. C., Logan, A. C., and Selhub, E. M. (2013a). Intestinal microbiota, probiotics and mental health: from metchnikoff to modern advances: part I autointoxication revisited. Gut Pathog. 5:5. doi: 10.1186/1757-4749-5-5

Bested, A. C., Logan, A. C., and Selhub, E. M. (2013b). Intestinal microbiota, probiotics and mental health: from metchnikoff to modern advances: part III convergence toward clinical trials. Gut Pathog. 5:4. doi: 10.1186/1757-4749-5-4

Bharwani, A., Mian, M. F., Foster, J. A., Surette, M. G., Bienenstock, J., and Forsythe, P. (2016). Structural \& functional consequences of chronic psychosocial stress on the microbiome \& host. Psychoneuroendocrinology 63, 2010-2025. doi: 10.1016/j.psyneuen.2015.10.001

Bian, X., Chi, L., Gao, B., Tu, P., Ru, H., and Lu, K. (2017). Gut microbiome response to sucralose and its potential role in inducing liver inflammation in mice. Front. Physiol. 8:487. doi: 10.3389/fphys.2017.00487

Bien-Ly, N., and Watts, R. J. (2014). The blood-brain barrier's gut check. Sci. Transl. Med. 6:263fs246. doi: 10.1126/scitranslmed.aaa2543

Blaser, M. J. (2016). Antibiotic use and its consequences for the normal microbiome. Science 352, 544-545. doi: 10.1126/science.aad 9358

Bloomfield, S. (2013). The hygiene hypothesis: identifying microbial friends and protecting against microbial enemies. Perspect. Public Health 133, 301-303. doi: 10.1177/1757913913506642

Bodnar, R. J. (2016). Endogenous opiates and behavior: 2014. Peptides 75, 18-70. doi: 10.1016/j.peptides.2015.10.009

Bodnar, R. J. (2017). Endogenous opiates and behavior: 2015. Peptides 88, 126-188. doi: 10.1016/j.peptides.2016. 12.004

Bokulich, N. A., Chung, J., Battaglia, T., Henderson, N., Jay, M., Li, H., et al. (2016) Antibiotics, birth mode, and diet shape microbiome maturation during early life. Sci. Transl. Med. 8:343ra382. doi: 10.1126/scitranslmed.aad7121

Bonaz, B., Bazin, T., and Pellissier, S. (2018). The vagus nerve at the interface of the microbiota-gut-brain axis. Front. Neurosci. 12:49. doi: 10.3389/fnins.2018. 00049

Borre, Y. E., O’Keeffe, G. W., Clarke, G., Stanton, C., Dinan, T. G., and Cryan, J. F. (2014). Microbiota and neurodevelopmental windows: implications for 
brain disorders. Trends Mol. Med. 20, 509-518. doi: 10.1016/j.molmed.2014. 05.002

Bourassa, M. W., Alim, I., Bultman, S. J., and Ratan, R. R. (2016). Butyrate, neuroepigenetics and the gut microbiome: can a high fiber diet improve brain health? Neurosci. Lett. 625, 56-63. doi: 10.1016/j.neulet.2016.02.009

Braniste, V., Al-Asmakh, M., Kowal, C., Anuar, F., Abbaspour, A., Toth, M., et al. (2014). The gut microbiota influences blood-brain barrier permeability in mice. Sci. Transl. Med. 6:263ra158. doi: 10.1126/scitranslmed.3009759

Bravo, J. A., Forsythe, P., Chew, M. V., Escaravage, E., Savignac, H. M., Dinan, T. G., et al. (2011). Ingestion of Lactobacillus strain regulates emotional behavior and central GABA receptor expression in a mouse via the vagus nerve. Proc. Natl. Acad. Sci. U.S.A. 108, 16050-16055. doi: 10.1073/pnas.1102999108

Bruce-Keller, A. J., Salbaum, J. M., and Berthoud, H. R. (2018). Harnessing gut microbes for mental health: getting from here to there. Biol. Psychiatry 83, 214-223. doi: 10.1016/j.biopsych.2017.08.014

Buffington, S. A., Di Prisco, G. V., Auchtung, T. A., Ajami, N. J., Petrosino, J. F., and Costa-Mattioli, M. (2016). Microbial reconstitution reverses maternal diet-induced social and synaptic deficits in offspring. Cell 165, 1762-1775. doi: 10.1016/j.cell.2016.06.001

Burcelin, R. M., Serino, M., Chabo, C., Garidou, L., Pomie, C., Courtney, M., et al. (2013). Metagenome and metabolism the tissue microbiota hypothesis. Diabetes Obes. Metab. 15, 61-70. doi: 10.1111/dom.12157

Burokas, A., Arboleya, S., Moloney, R. D., Peterson, V. L., Murphy, K., Clarke, G., et al. (2017). Targeting the microbiota-gut-brain axis: prebiotics have anxiolytic and antidepressant-like effects and reverse the impact of chronic stress in mice. Biol. Psychiatry 82, 472-487. doi: 10.1016/j.biopsych.2016.12.031

Cabral, A. (2013). Function of the microbiota. Best Pract. Res. Clin. Gastroenterol. 27, 5-16. doi: 10.1016/j.bpg.2013.03.006

Cammarota, G., Ianiro, G., Bibbo, S., and Gasbarrini, A. (2014). Gut microbiota modulation: probiotics, antibiotics or fecal microbiota transplantation? Intern. Emerg. Med. 9, 365-373. doi: 10.1007/s11739-014-1069-4

Carlson, A. L., Xia, K., Azcarate-Peril, M. A., Goldman, B. D., Ahn, M., Styner, M. A., et al. (2018). Infant gut microbiome associated with cognitive development. Biol. Psychiatry 83, 148-159. doi: 10.1016/j.biopsych.2017.06.021

Castanon, N., Luheshi, G., and Laye, S. (2015). Role of neuroinflammation in the emotional and cognitive alterations displayed by animal models of obesity. Front. Neurosci. 9:229. doi: 10.3389/fnins.2015.00229

Castillo-Ruiz, A., Mosley, M., George, A. J., Mussaji, L. F., Fullerton, E. F., Ruszkowski, E. M., et al. (2018). The microbiota influences cell death and microglial colonization in the perinatal mouse brain. Brain Behav. Immun. 67, 218-229. doi: 10.1016/j.bbi.2017.08.027

Cerdo, T., Ruiz, A., Suarez, A., and Campoy, C. (2017). Probiotic, prebiotic, and brain development. Nutrients 9:E1247. doi: 10.3390/nu911 1247

Chassaing, B., Koren, O., Goodrich, J. K., Poole, A. C., Srinivasan, S., Ley, R. E., et al. (2015). Dietary emulsifiers impact the mouse gut microbiota promoting colitis and metabolic syndrome. Nature 519, 92-96. doi: 10.1038/nature1 4232

Chassaing, B., Van de Wiele, T., De Bodt, J., Marzorati, M., and Gewirtz, A. T. (2017). Dietary emulsifiers directly alter human microbiota composition and gene expression ex vivo potentiating intestinal inflammation. Gut 66, 1414-1427. doi: 10.1136/gutjnl-2016-313099

Chen, J. J., Zeng, B. H., Li, W. W., Zhou, C. J., Fan, S. H., Cheng, K., et al. (2017). Effects of gut microbiota on the microRNA and mRNA expression in the hippocampus of mice. Behav. Brain Res. 322(Pt A), 34-41. doi: 10.1016/j. bbr.2017.01.021

Christian, L. M., Galley, J. D., Hade, E. M., Schoppe-Sullivan, S., Dush, C. K., and Bailey, M. T. (2015). Gut microbiome composition is associated with temperament during early childhood. Brain Behav. Immun. 45, 118-127. doi: 10.1016/j.bbi.2014.10.018

Claesson, M. J., Cusack, S., O'Sullivan, O., Greene-Diniz, R., and de Weerd, H. (2011). Composition, variability, and temporal stability of the intestinal microbiota of the elderly. Proc. Natl. Acad. Sci. U.S.A. 108, 4586-4591. doi: 10.1073/pnas.1000097107

Clarke, S. F., Murphy, E. F., O'Sullivan, O., Lucey, A. J., Humphreys, M., Hogan, A., et al. (2014). Exercise and associated dietary extremes impact on gut microbial diversity. Gut 63, 1913-1920. doi: 10.1136/gutjnl-2013306541
Clemente, J. C., Ursell, Luke, K., Parfrey, Laura, W., and Knight, R. (2012). The impact of the gut microbiota on human health: an integrative view. Cell 148, 1258-1270. doi: 10.1016/j.cell.2012.01.035

Collins, S. M., Kassam, Z., and Bercik, P. (2013). The adoptive transfer of behavioral phenotype via the intestinal microbiota: experimental evidence and clinical implications. Curr. Opin. Microbiol. 16, 240-245. doi: 10.1016/j.mib.2013. 06.004

Collins, S. M., Surette, M., and Bercik, P. (2012). The interplay between the intestinal microbiota and the brain. Nat. Rev. Microbiol. 10, 735-742. doi: $10.1038 /$ nrmicro2876

Cooper, D. N., Kable, M. E., Marco, M. L., De Leon, A., Rust, B., Baker, J. E., et al. (2017). The effects of moderate whole grain consumption on fasting glucose and lipids, gastrointestinal symptoms, and microbiota. Nutrients 9:E173. doi: $10.3390 /$ nu9020173

Cowan, C. S. M., Hoban, A. E., Ventura-Silva, A. P., Dinan, T. G., Clarke, G., and Cryan, J. F. (2017). Gutsy moves: the amygdala as a critical node in microbiota to brain signaling. Bioessays 40:1700172. doi: 10.1002/bies.20170 0172

Cox, L. M., and Weiner, H. L. (2018). Microbiota signaling pathways that influence neurologic disease. Neurotherapeutics 15, 135-145. doi: 10.1007/s13311-0170598-8

Crumeyrolle-Arias, M., Jaglin, M., Bruneau, A., Vancassel, S., Cardona, A., Dauge, V., et al. (2014). Absence of the gut microbiota enhances anxietylike behavior and neuroendocrine response to acute stress in rats. Psychoneuroendocrinology 42, 207-217. doi: 10.1016/j.psyneuen.2014.01.014

Cryan, J. F., and Dinan, T. G. (2012). Mind-altering microorganisms: the impact of the gut microbiota on brain and behaviour. Nat. Rev. Neurosci. 13, 701-712. doi: $10.1038 / \mathrm{nrn} 3346$

Cryan, J. F., and O'Mahony, S. M. (2011). The microbiome-gut-brain axis: from bowel to behavior. Neurogastroenterol. Motil. 23, 187-192. doi: 10.1111/j.13652982.2010.01664.x

Cussotto, S., Sandhu, K. V., Dinan, T. G., and Cryan, J. F. (2018). The neuroendocrinology of the microbiota-gut-brain axis: a behavioural perspective. Front. Neuroendocrinol. doi: 10.1016/j.yfrne.2018.04.002 [Epub ahead of print].

Dai, Y. J., Wang, H. Y., Wang, X. J., Kaye, A. D., and Sun, Y. H. (2017). Potential beneficial effects of probiotics on human migraine headache: a literature review. Pain Physician 20, E251-E255.

Daien, C. I., Pinget, G. V., Tan, J. K., and Macia, L. (2017). Detrimental impact of microbiota-accessible carbohydrate-deprived diet on gut and immune homeostasis: an overview. Front. Immunol. 8:548. doi: 10.3389/fimmu.2017. 00548

DALYs, G. B. D., and Collaborators, H. (2016). Global, regional, and national disability-adjusted life-years (DALYs) for 315 diseases and injuries and healthy life expectancy (HALE), 1990-2015: a systematic analysis for the global burden of disease study 2015. Lancet 388, 1603-1658. doi: 10.1016/S0140-6736(16) 31460-X

DALYs, G. B. D., and Collaborators, H. (2017). Global, regional, and national disability-adjusted life-years (DALYs) for 333 diseases and injuries and healthy life expectancy (HALE) for 195 countries and territories, 1990-2016: a systematic analysis for the global burden of disease study 2016. Lancet 390, 1260-1344. doi: 10.1016/S0140-6736(17)32130-X

Daulatzai, M. A. (2014). Chronic functional bowel syndrome enhances gut-brain axis dysfunction, neuroinflammation, cognitive impairment, and vulnerability to dementia. Neurochem. Res. 39, 624-644. doi: 10.1007/s11064-0141266-6

Davey, K. J., Cotter, P. D., O’Sullivan, O., Crispie, F., Dinan, T. G., Cryan, J. F., et al. (2013). Antipsychotics and the gut microbiome: olanzapine-induced metabolic dysfunction is attenuated by antibiotic administration in the rat. Transl. Psychiatry 3:e309. doi: 10.1038/tp.2013.83

David, L. A., Maurice, C. F., Carmody, R. N., Gootenberg, D. B., Button, J. E., Wolfe, B. E., et al. (2014). Diet rapidly and reproducibly alters the human gut microbiome. Nature 505, 559-563. doi: 10.1038/nature 12820

De Filippo, C., Di Paola, M., Ramazzotti, M., Albanese, D., Pieraccini, G., Banci, E., et al. (2017). Diet, environments, and gut microbiota. a preliminary investigation in children living in rural and urban burkina faso and italy. Front. Microbiol. 8:1979. doi: 10.3389/fmicb.2017.01979 
de Kort, S., Keszthelyi, D., and Masclee, A. A. (2011). Leaky gut and diabetes mellitus: what is the link? Obes. Rev. 12, 449-458. doi: 10.1111/j.1467-789X. 2010.00845.x

De Palma, G., Collins, S. M., Bercik, P., and Verdu, E. F. (2014). The microbiotagut-brain axis in gastrointestinal disorders: stressed bugs, stressed brain or both? J. Physiol. 592(Pt 14), 2989-2997. doi: 10.1113/jphysiol.2014.27 3995

Derrien, M., and Veiga, P. (2017). Rethinking diet to aid human-microbe symbiosis. Trends Microbiol. 25, 100-112. doi: 10.1016/j.tim.2016.09.011

Desbonnet, L., Clarke, G., Shanahan, F., Dinan, T. G., and Cryan, J. F. (2014). Microbiota is essential for social development in the mouse. Mol. Psychiatry 19, 146-148. doi: 10.1038/mp.2013.65

Desbonnet, L., Clarke, G., Traplin, A., O’Sullivan, O., Crispie, F., Moloney, R. D., et al. (2015). Gut microbiota depletion from early adolescence in mice: Implications for brain and behaviour. Brain Behav. Immun. 48, 165-173. doi: 10.1016/j.bbi.2015.04.004

Desbonnet, L., Garrett, L., Clarke, G., Bienenstock, J., and Dinan, T. G. (2008). The probiotic Bifidobacteria infantis: an assessment of potential antidepressant properties in the rat. J. Psychiatr. Res. 43, 164-174. doi: 10.1016/j.jpsychires. 2008.03.009

Desbonnet, L., Garrett, L., Clarke, G., Kiely, B., Cryan, J. F., and Dinan, T. G. (2010). Effects of the probiotic Bifidobacterium infantis in the maternal separation model of depression. Neuroscience 170, 1179-1188. doi: 10.1016/j.neuroscience. 2010.08.005

Di Mauro, A., Neu, J., Riezzo, G., Raimondi, F., Martinelli, D., Francavilla, R., et al. (2013). Gastrointestinal function development and microbiota. Ital. J. Pediatr. 39:15. doi: 10.1186/1824-7288-39-15

Diaz Heijtz, R. (2016). Fetal, neonatal, and infant microbiome: perturbations and subsequent effects on brain development and behavior. Semin. Fetal. Neonatal. Med. 21, 410-417. doi: 10.1016/j.siny.2016.04.012

Diaz Heijtz, R., Wang, S., Anuar, F., Qian, Y., Bjorkholm, B., Samuelsson, A., et al. (2011). Normal gut microbiota modulates brain development and behavior. Proc. Natl. Acad. Sci. U.S.A. 108, 3047-3052. doi: 10.1073/pnas.1010529108

Dickerson, F., Severance, E., and Yolken, R. (2017). The microbiome, immunity, and schizophrenia and bipolar disorder. Brain Behav. Immun. 62, 46-52. doi: 10.1016/j.bbi.2016.12.010

Dinan, T. G., and Cryan, J. F. (2012). Regulation of the stress response by the gut microbiota: implications for psychoneuroendocrinology. Psychoneuroendocrinology 37, 1369-1378. doi: 10.1016/j.psyneuen.2012.03.007

Dinan, T. G., and Cryan, J. F. (2017). Gut instincts: microbiota as a key regulator of brain development, ageing and neurodegeneration. J. Physiol. 595, 489-503. doi: 10.1113/JP273106

Dinan, T. G., Cryan, J. F., and Stanton, C. (2018). Gut microbes and brain development have black box connectivity. Biol. Psychiatry 83, 97-99. doi: 10.1016/j.biopsych.2017.11.005

Dinan, T. G., Stanton, C., and Cryan, J. F. (2013). Psychobiotics: a novel class of psychotropic. Biol. Psychiatry 74, 720-726. doi: 10.1016/j.biopsych.2013.05.001

Distrutti, E., O’Reilly, J. A., McDonald, C., Cipriani, S., Renga, B., Lynch, M. A., et al. (2014). Modulation of intestinal microbiota by the probiotic VSL\#3 resets brain gene expression and ameliorates the age-related deficit in LTP. PLoS One 9:e106503. doi: 10.1371/journal.pone.0106503

Doenyas, C. (2018). Gut microbiota, inflammation, and probiotics on neural development in autism spectrum disorder. Neuroscience 374, 271-286. doi: 10.1016/j.neuroscience.2018.01.060

Dolle, L., Tran, H. Q., Etienne-Mesmin, L., and Chassaing, B. (2016). Policing of gut microbiota by the adaptive immune system. BMC Med. 14:27. doi: 10.1186/ s12916-016-0573-y

Duan, Y., Wu, X., Liang, S., and Jin, F. (2015). Elevated blood ammonia level is a potential biological risk factor of behavioral disorders in prisoners. Behav. Neurol. 2015:797862. doi: 10.1155/2015/797862

Duncan, S. H., Belenguer, A., Holtrop, G., Johnstone, A. M., Flint, H. J., and Lobley, G. E. (2007). Reduced dietary intake of carbohydrates by obese subjects results in decreased concentrations of butyrate and butyrate-producing bacteria in feces. Appl. Environ. Microbiol. 73, 1073-1078. doi: 10.1128/AEM. 02340-06

Egert, M., Simmering, R., and Riedel, C. U. (2017). The association of the skin microbiota with health, immunity, and disease. Clin. Pharmacol. Ther. doi: 10.1002/cpt.698 [Epub ahead of print].
Elliott, D. E., and Weinstock, J. V. (2009). "Inflammatory bowel disease and the hygiene hypothesis: an argument for the role of helminths," in The Hygiene Hypothesis and Darwinian Medicine, ed. G. A. W. Rook (Berlin: Springer Science \& Business Media), 149-178.

Eloe-Fadrosh, E. A., and Rasko, D. A. (2013). The human microbiome: from symbiosis to pathogenesis. Annu. Rev. Med. 64, 145-163. doi: 10.1146/annurevmed-010312-133513

Engen, P. A., Green, S. J., Voigt, R. M., Forsyth, C. B., and Keshavarzian, A. (2015). The gastrointestinal microbiome: alcohol effects on the composition of intestinal microbiota. Alcohol Res. 37, 223-236.

Erny, D., Hrabe de Angelis, A. L., Jaitin, D., Wieghofer, P., Staszewski, O., David, E., et al. (2015). Host microbiota constantly control maturation and function of microglia in the CNS. Nat. Neurosci. 18, 965-977. doi: 10.1038/nn.4030

Eutamene, H., and Bueno, L. (2007). Role of probiotics in correcting abnormalities of colonic flora induced by stress. Gut 56, 1495-1497. doi: 10.1136/gut.2007. 124040

Evans, S., Chang, Y.-W., Burant, C., and McInnis, M. (2017). The effect of dietary omega- 6 fatty acids on inflammatory profiles differs in bipolar subjects with potential mediation by the microbiomic complement. Biol. Psychiatry 81:S15. doi: 10.1016/j.biopsych.2017.02.046

Evans, S. J., Bassis, C. M., Hein, R., Assari, S., Flowers, S. A., Kelly, M. B., et al. (2017). The gut microbiome composition associates with bipolar disorder and illness severity. J. Psychiatr. Res. 87, 23-29. doi: 10.1016/j.jpsychires.2016.12.007

Evrensel, A., and Ceylan, M. E. (2016). Fecal microbiota transplantation and its usage in neuropsychiatric disorders. Clin. Psychopharmacol. Neurosci. 14, 231-237. doi: 10.9758/cpn.2016.14.3.231

Faith, J. J., Guruge, J. L., Charbonneau, M., Subramanian, S., Seedorf, H., Goodman, A. L., et al. (2013). The long-term stability of the human gut microbiota. Science 341:1237439. doi: 10.1126/science.1237439

Fang, S., and Evans, R. M. (2013). Microbiology: wealth management in the gut. Nature 500, 538-539. doi: 10.1038/500538a

Fasano, A. (2012). Leaky gut and autoimmune diseases. Clin. Rev. Allergy Immunol. 42, 71-78. doi: 10.1007/s12016-011-8291-x

Ferreira, C., and Veldhoen, M. (2012). Host and microbes date exclusively. Cell 149, 1428-1430. doi: 10.1016/j.cell.2012.06.005

Fineberg, S. K., and Ross, D. A. (2017). Oxytocin and the Social Brain. Biol. Psychiatry 81, e19-e21. doi: 10.1016/j.biopsych.2016.11.004

Fink, M. P. (1990). Leaky gut hypothesis - a historical-perspective. Crit. Care Med. 18, 579-580. doi: 10.1097/00003246-199005000-00024

Fond, G., Boukouaci, W., Chevalier, G., Regnault, A., Eberl, G., Hamdani, N., et al. (2015). The "psychomicrobiotic": targeting microbiota in major psychiatric disorders: a systematic review. Pathol. Biol. 63, 35-42. doi: 10.1016/j.patbio. 2014.10.003

Forsythe, P., Bienenstock, J., and Kunze, W. A. (2014). Vagal pathways for microbiome-brain-gut axis communication. Adv. Exp. Med. Biol. 817, 115-133. doi: 10.1007/978-1-4939-0897-4_5

Forsythe, P., and Kunze, W. A. (2012). "Voices from within gut microbes and the CNS," in Cellular and Molecular Life Sciences, ed. K. Eichmann (Berlin: Springer Science and Business Media), 1-15.

Forsythe, P., Sudo, N., Dinan, T., Taylor, V. H., and Bienenstock, J. (2010). Mood and gut feelings. Brain Behav. Immun. 24, 9-16. doi: 10.1016/j.bbi.2009.05.058

Foster, J. A., Lyte, M., Meyer, E., and Cryan, J. F. (2016). Gut microbiota and brain function: an evolving field in neuroscience. Int. J. Neuropsychopharmacol. 19:pyv114. doi: 10.1093/ijnp/pyv114

Fraune, S., and Bosch, T. C. (2010). Why bacteria matter in animal development and evolution. Bioessays 32, 571-580. doi: 10.1002/bies.200900192

Freestone, P. P. E., Sandrini, S. M., Haigh, R. D., and Lyte, M. (2008). Microbial endocrinology: how stress influences susceptibility to infection. Trends Microbiol. 16, 55-64. doi: 10.1016/j.tim.2007.11.005

Friedland, R. P., and Chapman, M. R. (2017). The role of microbial amyloid in neurodegeneration. PLoS Pathog. 13:e1006654. doi: 10.1371/journal.ppat. 1006654

Frohlich, E. E., Farzi, A., Mayerhofer, R., Reichmann, F., Jacan, A., Wagner, B., et al. (2016). Cognitive impairment by antibiotic-induced gut dysbiosis: analysis of gut microbiota-brain communication. Brain Behav. Immun. 56, 140-155. doi: 10.1016/j.bbi.2016.02.020

Galland, L. (2014). The gut microbiome and the brain. J. Med. Food 17, 1261-1272. doi: $10.1089 /$ jmf.2014.7000 
Garcia Bueno, B., Caso, J. R., Madrigal, J. L., and Leza, J. C. (2016). Innate immune receptor toll-like receptor 4 signalling in neuropsychiatric diseases. Neurosci. Biobehav. Rev. 64, 134-147. doi: 10.1016/j.neubiorev.2016.02.013

Garcia-Pena, C., Alvarez-Cisneros, T., Quiroz-Baez, R., and Friedland, R. P. (2017). Microbiota and aging. a review and commentary. Arch. Med. Res. 48, 681-689. doi: 10.1016/j.arcmed.2017.11.005

Gareau, M. G. (2016). Cognitive function and the microbiome. Int. Rev. Neurobiol. 131, 227-246. doi: 10.1016/bs.irn.2016.08.001

Gareau, M. G., Jury, J., MacQueen, G., Sherman, P. M., and Perdue, M. H. (2007). Probiotic treatment of rat pups normalises corticosterone release and ameliorates colonic dysfunction induced by maternal separation. Gut 56, 1522-1528. doi: 10.1136/gut.2006.117176

Gawronska, A., Dziechciarz, P., Horvath, A., and Szajewska, H. (2007). A randomized double-blind placebo-controlled trial of Lactobacillus GG for abdominal pain disorders in children. Aliment. Pharmacol. Ther. 25, 177-184. doi: $10.1111 /$ j.1365-2036.2006.03175.x

Gazzaniga, F. S., and Kasper, D. L. (2016). Veggies and intact grains a day keep the pathogens away. Cell 167, 1161-1162. doi: 10.1016/j.cell.2016.10.047

GBD 2015 Neurological Disorders Collaborator Group (2017). Global, regional, and national burden of neurological disorders during 1990-2015: a systematic analysis for the global burden of disease study 2015. Lancet Neurol. 16, 877-897. doi: 10.1016/S1474-4422(17)30299-5

Gensollen, T., Iyer, S. S., Kasper, D. L., and Blumberg, R. S. (2016). How colonization by microbiota in early life shapes the immune system. Science 352, 539-544. doi: 10.1126/science.aad9378

Geuking, M. B., Koller, Y., Rupp, S., and McCoy, K. D. (2014). The interplay between the gut microbiota and the immune system. Gut Microbes 5, 411-418. doi: 10.4161/gmic. 29330

Gholizadeh, P., Eslami, H., Yousefi, M., Asgharzadeh, M., Aghazadeh, M., and Kafil, H. S. (2016). Role of oral microbiome on oral cancers, a review. Biomed. Pharmacother. 84, 552-558. doi: 10.1016/j.biopha.2016.09.082

Gibson, G. R., Hutkins, R., Sanders, M. E., Prescott, S. L., Reimer, R. A., Salminen, S. J., et al. (2017). Expert consensus document: the International Scientific Association for Probiotics and Prebiotics (ISAPP) consensus statement on the definition and scope of prebiotics. Nat. Rev. Gastroenterol. Hepatol. 14, 491-502. doi: $10.1038 /$ nrgastro.2017.75

Girolamo, F., Coppola, C., and Ribatti, D. (2017). Immunoregulatory effect of mast cells influenced by microbes in neurodegenerative diseases. Brain Behav. Immun. 65, 68-89. doi: 10.1016/j.bbi.2017.06.017

Glenny, E. M., Bulik-Sullivan, E. C., Tang, Q., Bulik, C. M., and Carroll, I. M. (2017). Eating disorders and the intestinal microbiota: mechanisms of energy homeostasis and behavioral influence. Curr. Psychiatry Rep. 19:51. doi: 10.1007/ s11920-017-0797-3

Gomez, A. (2017). Loss of gut microbiome diversity in industrialized societies: alternative views (comment on Doi 10.1002/bies.201600145). Bioessays 39:1700005. doi: 10.1002/bies.201700005

Gong, L., Cao, W., Chi, H., Wang, J., Zhang, H., Liu, J., et al. (2018). Whole cereal grains and potential health effects: involvement of the gut microbiota. Food Res. Int. 103, 84-102. doi: 10.1016/j.foodres.2017.10.025

Grenham, S., Clarke, G., Cryan, J. F., and Dinan, T. G. (2011). Brain-gut-microbe communication in health and disease. Front. Physiol. 2:94. doi: 10.3389/fphys. 2011.00094

Group, N. P. (2008). Who are we. Nature 453:563. doi: 10.1038/453563a

Gur, T. L., Worly, B. L., and Bailey, M. T. (2015). Stress and the commensal microbiota: importance in parturition and infant neurodevelopment. Front. Psychiatry 6:5. doi: 10.3389/fpsyt.2015.00005

Gutierrez-Diaz, I., Fernandez-Navarro, T., Sanchez, B., Margolles, A., and Gonzalez, S. (2016). Mediterranean diet and faecal microbiota: a transversal study. Food Funct. 7, 2347-2356. doi: 10.1039/c6fo00105j

Hallgren, M., Herring, M. P., Owen, N., Dunstan, D., Ekblom, O., Helgadottir, B., et al. (2016). Exercise, physical activity, and sedentary behavior in the treatment of depression: broadening the scientific perspectives and clinical opportunities. Front. Psychiatry 7:36. doi: 10.3389/fpsyt.2016.00036

Hamdani, N., Boukouaci, W., Hallouche, M. R., Charron, D., Krishnamoorthy, R., Leboyer, M., et al. (2015). Resolution of a manic episode treated with activated charcoal: evidence for a brain-gut axis in bipolar disorder. Aust. N. Z. J. Psychiatry 49, 1221-1223. doi: 10.1177/0004867415595873
Hamer, H. M., Preter, V. D., Preter, V. D., and Verbeke, K. (2012). Functional analysis of colonic bacterial metabolism: relevant to health? Am. J. Physiol. Gastrointest. Liver Physiol. 302, G1-G9. doi: 10.1152/ajpgi.00048.2011.-With

Hansson, J., Bosco, N., Favre, L., Raymond, F., Oliveira, M., Metairon, S., et al. (2011). Influence of gut microbiota on mouse B2 B cell ontogeny and function. Mol. Immunol. 48, 1091-1101. doi: 10.1016/j.molimm.2011.02.002

He, M., and Shi, B. (2017). Gut microbiota as a potential target of metabolic syndrome: the role of probiotics and prebiotics. Cell Biosci. 7:54. doi: 10.1186/ s13578-017-0183-1

He, Z., Cui, B. T., Zhang, T., Li, P., Long, C. Y., Ji, G. Z., et al. (2017). Fecal microbiota transplantation cured epilepsy in a case with Crohn's disease: the first report. World J. Gastroenterol. 23, 3565-3568. doi: 10.3748/wjg.v23.i19. 3565

Hearing, M., Graziane, N., Dong, Y., and Thomas, M. J. (2018). Opioid and psychostimulant plasticity: targeting overlap in nucleus accumbens glutamate signaling. Trends Pharmacol. Sci. 39, 276-294. doi: 10.1016/j.tips.2017.12.004

Hoban, A. E., Stilling, R. M., Moloney, G., Shanahan, F., Dinan, T. G., Clarke, G., et al. (2017). The microbiome regulates amygdala-dependent fear recall. Mol. Psychiatry 23, 1134-1144. doi: 10.1038/mp.2017.100

Hoban, A. E., Stilling, R. M., Ryan, F. J., Shanahan, F., Dinan, T. G., Claesson, M. J., et al. (2016). Regulation of prefrontal cortex myelination by the microbiota. Transl. Psychiatry 6:e774. doi: 10.1038/tp.2016.42

Hoffman, J. D., Parikh, I., Green, S. J., Chlipala, G., Mohney, R. P., Keaton, M., et al. (2017). Age drives distortion of brain metabolic, vascular and cognitive functions, and the gut microbiome. Front. Aging Neurosci. 9:298. doi: 10.3389/ fnagi.2017.00298

Holzer, P. (2016). Neuropeptides, microbiota, and behavior. Int. Rev. Neurobiol. 131, 67-89. doi: 10.1016/bs.irn.2016.08.005

Holzer, P., and Farzi, A. (2014). Neuropeptides and the microbiota-gut-brain axis. Adv. Exp. Med. Biol. 817, 195-219. doi: 10.1007/978-1-4939-0897-4_9

Holzer, P., Reichmann, F., and Farzi, A. (2012). Neuropeptide Y, peptide YY and pancreatic polypeptide in the gut-brain axis. Neuropeptides 46, 261-274. doi: 10.1016/j.npep.2012.08.005

Honda, K., and Littman, D. R. (2016). The microbiota in adaptive immune homeostasis and disease. Nature 535, 75-84. doi: 10.1038/nature 18848

Hu, X., Wang, T., and Jin, F. (2016). Alzheimer's disease and gut microbiota. Sci. China Life Sci. 59, 1006-1023. doi: 10.1007/s11427-016-5083-9

Hu, X., Wang, T., Liang, S., Li, W., Wu, X., and Jin, F. (2015). Antibiotic-induced imbalances in gut microbiota aggravates cholesterol accumulation and liver injuries in rats fed a high-cholesterol diet. Appl. Microbiol. Biotechnol. 99, 9111-9122. doi: 10.1007/s00253-015-6753-4

Hu, X., Wang, T., Luo, J., Liang, S., Li, W., Wu, X., et al. (2014). Age-dependent effect of high cholesterol diets on anxiety-like behavior in elevated plus maze test in rats. Behav. Brain Funct. 10:30. doi: 10.1186/1744-9081-10-30

Human Microbiome Project Consortium. (2012). Structure, function and diversity of the healthy human microbiome. Nature 486, 207-214. doi: 10.1038/ nature 11234

Humphries, C. (2017). Microbiome: detecting diversity. Nature 550, S12-S14. doi: $10.1038 / 550$ S12a

Jacka, F. N. (2017). Nutritional psychiatry: where to next? eBiomedicine 17, 24-29. doi: 10.1016/j.ebiom.2017.02.020

Jiang, H., Ling, Z., Zhang, Y., Mao, H., Ma, Z., Yin, Y., et al. (2015). Altered fecal microbiota composition in patients with major depressive disorder. Brain Behav. Immun. 48, 186-194. doi: 10.1016/j.bbi.2015.03.016

Jiang, Z., Zhao, M., Zhang, H., Li, Y., Liu, M., and Feng, F. (2017). Antimicrobial emulsifier - glycerol monolaurate induces metabolic syndrome, gut microbiota dysbiosis and systemic low-grade inflammation in low-fat diet fed mice. Mol. Nutr. Food Res. 62:1700547. doi: 10.1002/mnfr.201700547

Jin, Y., Wu, S., Zeng, Z., and Fu, Z. (2017). Effects of environmental pollutants on gut microbiota. Environ. Pollut. 222, 1-9. doi: 10.1016/j.envpol.2016.11.045

Joshipura, K. J., Munoz-Torres, F. J., Morou-Bermudez, E., and Patel, R. P. (2017). Over-the-counter mouthwash use and risk of pre-diabetes/diabetes. Nitric Oxide 71, 14-20. doi: 10.1016/j.niox.2017.09.004

Kang, D. W., Adams, J. B., Gregory, A. C., Borody, T., Chittick, L., Fasano, A., et al. (2017). Microbiota transfer therapy alters gut ecosystem and improves gastrointestinal and autism symptoms: an open-label study. Microbiome 5:10. doi: 10.1186/s40168-016-0225-7 
Kantak, P. A., Bobrow, D. N., and Nyby, J. G. (2014). Obsessive-compulsivelike behaviors in house mice are attenuated by a probiotic (Lactobacillus rhamnosus GG). Behav. Pharmacol. 25, 71-79. doi: 10.1097/FBP.00000000000 00013

Kaur, I. P., Kuhad, A., Garg, A., and Chopra, K. (2009). Probiotics: delineation of prophylactic and therapeutic benefits. J. Med. Food 12, 219-235. doi: 10.1089/ jmf.2007.0544

Keightley, P. C., Koloski, N. A., and Talley, N. J. (2015). Pathways in gut-brain communication: evidence for distinct gut-to-brain and brainto-gut syndromes. Aust. N. Z. J. Psychiatry 49, 207-214. doi: 10.1177/ 0004867415569801

Kelly, J. R., Borre, Y., O', Brien C, Patterson, E., El, Aidy S, Deane, J., et al. (2016). Transferring the blues: depression-associated gut microbiota induces neurobehavioural changes in the rat. J. Psychiatr. Res. 82, 109-118. doi: 10.1016/ j.jpsychires.2016.07.019

Kelly, J. R., Kennedy, P. J., Cryan, J. F., Dinan, T. G., Clarke, G., and Hyland, N. P. (2015). Breaking down the barriers: the gut microbiome, intestinal permeability and stress-related psychiatric disorders. Front. Cell. Neurosci. 9:392. doi: 10.3389/fncel.2015.00392

Kelly, J. R., Minuto, C., Cryan, J. F., Clarke, G., and Dinan, T. G. (2017). Cross talk: the microbiota and neurodevelopmental disorders. Front. Neurosci. 11:490. doi: 10.3389/fnins.2017.00490

Kennedy, P. J., Cryan, J. F., Dinan, T. G., and Clarke, G. (2017). Kynurenine pathway metabolism and the microbiota-gut-brain axis. Neuropharmacology 112(Pt B), 399-412. doi: 10.1016/j.neuropharm.2016. 07.002

Khalyfa, A., Poroyko, V. A., Qiao, Z., Gileles-Hillel, A., Khalyfa, A. A., Akbarpour, M., et al. (2017). Exosomes and metabolic function in mice exposed to alternating dark-light cycles mimicking night shift work schedules. Front. Physiol. 8:882. doi: 10.3389/fphys.2017.00882

Kibe, R., Kurihara, S., Sakai, Y., Suzuki, H., Ooga, T., Sawaki, E., et al. (2014). Upregulation of colonic luminal polyamines produced by intestinal microbiota delays senescence in mice. Sci. Rep. 4:4548. doi: 10.1038/srep04548

Kim, H. N., Yun, Y., Ryu, S., Chang, Y., Kwon, M. J., Cho, J., et al. (2017). Correlation between gut microbiota and personality in adults: a cross-sectional study. Brain Behav. Immun. 69, 374-385. doi: 10.1016/j.bbi.2017.12.012

Kim, S., Kim, H., Yim, Y. S., Ha, S., Atarashi, K., Tan, T. G., et al. (2017). Maternal gut bacteria promote neurodevelopmental abnormalities in mouse offspring. Nature 549, 528-532. doi: 10.1038/nature23910

Kim, Y. A., Keogh, J. B., and Clifton, P. M. (2017). Probiotics, prebiotics, synbiotics and insulin sensitivity. Nutr. Res. Rev. 31, 1-17. doi: 10.1017/ S095442241700018X

Kim, M., Qie, Y., Park, J., and Kim, C. H. (2016). Gut microbial metabolites fuel host antibody responses. Cell Host Microbe 20, 202-214. doi: 10.1016/j.chom. 2016.07.001

Kiraly, D. D., Walker, D. M., Calipari, E. S., Labonte, B., Issler, O., Pena, C. J., et al. (2016). Alterations of the host microbiome affect behavioral responses to cocaine. Sci. Rep. 6:35455. doi: 10.1038/srep35455

Knoop, K. A., Gustafsson, J. K., McDonald, K. G., Kulkarni, D. H., Coughlin, P. E., McCrate, S., et al. (2017). Microbial antigen encounter during a preweaning interval is critical for tolerance to gut bacteria. Sci. Immunol. 2:eaao1314. doi: 10.1126/sciimmunol.aao1314

Koh, A., De Vadder, F., Kovatcheva-Datchary, P., and Backhed, F. (2016). From dietary fiber to host physiology: short-chain fatty acids as key bacterial metabolites. Cell 165, 1332-1345. doi: 10.1016/j.cell.2016.05.041

Kong, F., Zhao, J., Han, S., Zeng, B., Yang, J., Si, X., et al. (2014). Characterization of the gut microbiota in the red panda (Ailurus fulgens). PLoS One 9:e87885. doi: 10.1371/journal.pone.0087885

Kramer, A., Bekeschus, S., Broker, B. M., Schleibinger, H., Razavi, B., and Assadian, O. (2013). Maintaining health by balancing microbial exposure and prevention of infection: the hygiene hypothesis versus the hypothesis of early immune challenge. J. Hosp. Infect. 83, S29-S34. doi: 10.1016/S0195-6701(13) 60007-9

Kundu, P., Blacher, E., Elinav, E., and Pettersson, S. (2017). Our gut microbiome: the evolving inner self. Cell 171, 1481-1493. doi: 10.1016/j.cell.2017.11.024

Lach, G., Schellekens, H., Dinan, T. G., and Cryan, J. F. (2017). Anxiety, depression, and the microbiome: a role for gut peptides. Neurotherapeutics 15, 36-59. doi: $10.1007 /$ s13311-017-0585-0
Lakhan, S. E., and Vieira, K. F. (2008). Nutritional therapies for mental disorders. Nutr. J. 7:2. doi: 10.1186/1475-2891-7-2

Lang, U. E., Beglinger, C., Schweinfurth, N., Walter, M., and Borgwardt, S. (2015). Nutritional aspects of depression. Cell. Physiol. Biochem. 37, 1029-1043. doi: 10.1159/000430229

Lazaro, C. P., Ponde, M. P., and Rodrigues, L. E. (2016). Opioid peptides and gastrointestinal symptoms in autism spectrum disorders. Rev. Bras. Psiquiatr. 38, 243-246. doi: 10.1590/1516-4446-2015-1777

Le Floc'h, N., Otten, W., and Merlot, E. (2011). Tryptophan metabolism, from nutrition to potential therapeutic applications. Amino Acids 41, 1195-1205. doi: 10.1007/s00726-010-0752-7

Leclercq, S., Cani, P. D., Neyrinck, A. M., Starkel, P., Jamar, F., Mikolajczak, M., et al. (2012). Role of intestinal permeability and inflammation in the biological and behavioral control of alcohol-dependent subjects. Brain Behav. Immun. 26, 911-918. doi: 10.1016/j.bbi.2012.04.001

Leclercq, S., Forsythe, P., and Bienenstock, J. (2016). Posttraumatic stress disorder: does the gut microbiome hold the key? Can. J. Psychiatry 61, 204-213. doi: 10.1177/0706743716635535

Ledford, H. (2014). Medical research: if depression were cancer. Nature 515, 182-184. doi: 10.1038/515182a

Lee, Y. K., and Mazmanian, S. K. (2010). Has the microbiota played a critical role in the evolution of the adaptive immune system? Science 330, 1768-1773. doi: 10.1126/science. 1195568

Lee, Y. K., Menezes, J. S., Umesaki, Y., and Mazmanian, S. K. (2011). Proinflammatory T-cell responses to gut microbiota promote experimental autoimmune encephalomyelitis. Proc. Natl. Acad. Sci. U.S.A. 108(Suppl. 1), 4615-4622. doi: 10.1073/pnas. 1000082107

Lerner, A., Neidhofer, S., and Matthias, T. (2017). The gut microbiome feelings of the brain: a perspective for non-microbiologists. Microorganisms 5:E66. doi: 10.3390/microorganisms5040066

Leulier, F., MacNeil, L. T., Lee, W. J., Rawls, J. F., Cani, P. D., Schwarzer, M., et al. (2017). Integrative physiology: at the crossroads of nutrition, microbiota animal physiology, and human health. Cell Metab. 25, 522-534. doi: 10.1016/j. cmet.2017.02.001

Levy, M., Kolodziejczyk, A. A., Thaiss, C. A., and Elinav, E. (2017). Dysbiosis and the immune system. Nat. Rev. Immunol. 17, 219-232. doi: 10.1038/nri.2017.7

Li, J., Hou, Q., Zhang, J., Xu, H., Sun, Z., Menghe, B., et al. (2017). Carbohydrate staple food modulates gut microbiota of mongolians in China. Front. Microbiol. 8:484. doi: $10.3389 /$ fmicb.2017.00484

Li, W., Wu, X., Hu, X., Wang, T., Liang, S., Duan, Y., et al. (2017). Structural changes of gut microbiota in Parkinson's disease and its correlation with clinical features. Sci. China Life Sci. 60, 1223-1233. doi: 10.1007/s11427-016-9001-4

Liang, S., Wang, T., Hu, X., Li, W., Jin, F., and Wang, L. (2012). Microorganism and behavior and psychiatric disorders (Article in Chinese). Adv. Psychol. Sci. 20, 75-97. doi: 10.3724/SP.J.1042.2012.00075

Liang, S., Wang, T., Hu, X., Luo, J., Li, W., Wu, X., et al. (2015). Administration of Lactobacillus helveticus NS8 improves behavioral, cognitive, and biochemical aberrations caused by chronic restraint stress. Neuroscience 310, 561-577. doi: 10.1016/j.neuroscience.2015.09.033

Liang, S., Wu, X., Hu, X., Niu, Y., and Jin, F. (2018a). The development and tendency of depression researches: viewed from the microbiota-gut-brain axis (Article in Chinese). Chin. Sci. Bull. 63, 2010-2025. doi: 10.1360/N97201701182

Liang, S., Wu, X., Hu, X., Wang, T., and Jin, F. (2018b). Recognizing depression from the microbiota(-)gut(-)brain axis. Int. J. Mol. Sci. 19:1592. doi: 10.3390/ ijms19061592

Liddle, R. A. (2018). Parkinson's disease from the gut. Brain Res. 1693(Pt B), 201-206. doi: 10.1016/j.brainres.2018.01.010

Lim, E. S., Wang, D., and Holtz, L. R. (2016). The bacterial microbiome and virome milestones of infant development. Trends Microbiol. 24, 801-810. doi: 10.1016/j.tim.2016.06.001

Limon, J. J., Skalski, J. H., and Underhill, D. M. (2017). Commensal fungi in health and disease. Cell Host Microbe 22, 156-165. doi: 10.1016/j.chom.2017.07.002

Liu, X., Cao, S., and Zhang, X. (2015). Modulation of gut microbiota-brain axis by probiotics. J. Agric. Food Chem. 63, 7885-7895. doi: 10.1021/acs.jafc.5b02404

Luczynski, P., McVey Neufeld, K. A., Oriach, C. S., Clarke, G., Dinan, T. G., and Cryan, J. F. (2016). Growing up in a bubble: using germfree animals to assess the influence of the gut microbiota on brain 
and behavior. Int. J. Neuropsychopharmacol. 19:pyw020. doi: 10.1093/ijnp/ pyw020

Luczynski, P., Tramullas, M., Viola, M., Shanahan, F., Clarke, G., O’Mahony, S., et al. (2017). Microbiota regulates visceral pain in the mouse. eLife 6:e25887. doi: 10.7554/eLife.25887

Luo, J., Wang, T., Liang, S., Hu, X., Li, W., and Jin, F. (2014). Ingestion of Lactobacillus strain reduces anxiety and improves cognitive function in the hyperammonemia rat. Sci. China Life Sci. 57, 327-335. doi: 10.1007/s11427014-4615-4

Lurie, I., Yang, Y. X., Haynes, K., Mamtani, R., and Boursi, B. (2015). Antibiotic exposure and the risk for depression, anxiety, or psychosis: a nested case-control study. J. Clin. Psychiatry 76, 1522-1528. doi: 10.4088/JCP.15m09961

Lyte, M. (2010). The microbial organ in the gut as a driver of homeostasis and disease. Med. Hypotheses 74, 634-638. doi: 10.1016/j.mehy.2009.10.025

Lyte, M. (2013). Microbial endocrinology in the microbiome-gut-brain axis: how bacterial production and utilization of neurochemicals influence behavior. Plos Pathog. 9:e1003726. doi: 10.1371/journal.ppat.1003726

Lyte, M. (2014a). Microbial endocrinology and the microbiota-gut-brain axis. $A d v$. Exp. Med. Biol. 817, 3-24. doi: 10.1007/978-1-4939-0897-4_1

Lyte, M. (2014b). Microbial endocrinology: host-microbiota neuroendocrine interactions influencing brain and behavior. Gut Microbes 5, 381-389. doi: 10.4161 /gmic. 28682

Lyte, M., Li, W., Opitz, N., Gaykema, R. P., and Goehler, L. E. (2006). Induction of anxiety-like behavior in mice during the initial stages of infection with the agent of murine colonic hyperplasia Citrobacter rodentium. Physiol. Behav. 89, 350-357. doi: 10.1016/j.physbeh.2006.06.019

Magnusson, K. R., Hauck, L., Jeffrey, B. M., Elias, V., Humphrey, A., Nath, R., et al. (2015). Relationships between diet-related changes in the gut microbiome and cognitive flexibility. Neuroscience 300, 128-140. doi: 10.1016/j.neuroscience. 2015.05.016

Man, W. H., de Steenhuijsen Piters, W. A., and Bogaert, D. (2017). The microbiota of the respiratory tract: gatekeeper to respiratory health. Nat. Rev. Microbiol. 15, 259-270. doi: 10.1038/nrmicro.2017.14

Mancabelli, L., Milani, C., Lugli, G. A., Turroni, F., Ferrario, C., van Sinderen, D., et al. (2017). Meta-analysis of the human gut microbiome from urbanized and pre-agricultural populations. Environ. Microbiol. 19, 1379-1390. doi: 10.1111/ 1462-2920.13692

Manco, M. (2012). Gut microbiota and developmental programming of the brain: from evidence in behavioral endophenotypes to novel perspective in obesity. Front. Cell. Infect. Microbiol. 2:109. doi: 10.3389/fcimb.2012. 00109

Mancuso, C., and Santangelo, R. (2017). Alzheimer's disease and gut microbiota modifications: the long way between preclinical studies and clinical evidence. Pharmacol. Res. 129, 329-336. doi: 10.1016/j.phrs.2017.12.009

Manderino, L., Carroll, I., Azcarate-Peril, M. A., Rochette, A., Heinberg, L., Peat, C., et al. (2017). Preliminary evidence for an association between the composition of the gut microbiome and cognitive function in neurologically healthy older adults. J. Int. Neuropsychol. Soc. 23, 700-705. doi: 10.1017/ S1355617717000492

Manrique, P., Dills, M., and Young, M. J. (2017). The human gut phage community and its implications for health and disease. Viruses 9:E141. doi: 10.3390/ v9060141

Maqsood, R., and Stone, T. W. (2016). The gut-brain axis, BDNF, NMDA and CNS disorders. Neurochem. Res. 41, 2819-2835. doi: 10.1007/s11064-0162039-1

Maranduba, C. M., De Castro, S. B., de Souza, G. T., Rossato, C., da Guia, F. C., Valente, M. A., et al. (2015). Intestinal microbiota as modulators of the immune system and neuroimmune system: impact on the host health and homeostasis. J. Immunol. Res. 2015:931574. doi: 10.1155/2015/931574

Margolis, K. G., Stevanovic, K., Li, Z., Yang, Q. M., Oravecz, T., Zambrowicz, B., et al. (2014). Pharmacological reduction of mucosal but not neuronal serotonin opposes inflammation in mouse intestine. Gut 63, 928-937. doi: 10.1136/gutjnl2013-304901

Marizzoni, M., Provasi, S., Cattaneo, A., and Frisoni, G. B. (2017). Microbiota and neurodegenerative diseases. Curr. Opin. Neurol. 30, 630-638. doi: 10.1097/ WCO.0000000000000496

Markle, J. G. M., Frank, D. N., Mortin-Toth, S., Robertson, C. E., Feazel, L. M., Rolle-Kampczyk, U., et al. (2013). Sex differences in the gut microbiome drive hormone-dependent regulation of autoimmunity. Science 339, 1084-1088. doi: $10.1126 /$ science. 1233521

Marques, T. M., Cryan, J. F., Shanahan, F., Fitzgerald, G. F., Ross, R. P., Dinan, T. G., et al. (2014). Gut microbiota modulation and implications for host health: dietary strategies to influence the gut-brain axis. Innov. Food Sci. Emerg. Technol. 22, 239-247. doi: 10.1016/j.ifset.2013.10.016

Matcovitch-Natan, O., Winter, D. R., Giladi, A., Vargas Aguilar, S., Spinrad, A., Sarrazin, S., et al. (2016). Microglia development follows a stepwise program to regulate brain homeostasis. Science 353:aad8670. doi: 10.1126/science.aad8670

Mayer, E. A., Knight, R., Mazmanian, S. K., Cryan, J. F., and Tillisch, K. (2014a). Gut microbes and the brain: paradigm shift in neuroscience. J. Neurosci. 34, 15490-15496. doi: 10.1523/JNEUROSCI.3299-14.2014

Mayer, E. A., Padua, D., and Tillisch, K. (2014b). Altered brain-gut axis in autism: comorbidity or causative mechanisms? Bioessays 36, 933-939. doi: 10.1002/bies. 201400075

Mayer, E. A., Tillisch, K., and Gupta, A. (2015). Gut/brain axis and the microbiota. J. Clin. Invest. 125, 926-938. doi: 10.1172/JCI76304

Mazzoli, R., and Pessione, E. (2016). The neuro-endocrinological role of microbial glutamate and GABA signaling. Front. Microbiol. 7:1934. doi: 10.3389/fmicb. 2016.01934

McCoy, K. D., Ronchi, F., and Geuking, M. B. (2017). Host-microbiota interactions and adaptive immunity. Immunol. Rev. 279, 63-69. doi: 10.1111/imr.12575

McCusker, R. H., and Kelley, K. W. (2013). Immune-neural connections: how the immune system's response to infectious agents influences behavior. J. Exp. Biol. 216(Pt 1), 84-98. doi: 10.1242/jeb.073411

McFall-Ngai, M., Hadfield, M. G., Bosch, T. C. G., Carey, H. V., and DomazetLoso, T. (2013). Animals in a bacterial world, a new imperative for the life sciences. Proc. Natl. Acad. Sci. U.S.A. 110, 3229-3236. doi: 10.1073/pnas. 1218525110/-/DCSupplemental

McKean, J., Naug, H., Nikbakht, E., Amiet, B., and Colson, N. (2017). Probiotics and subclinical psychological symptoms in healthy participants: a systematic review and meta-analysis. J. Altern. Complement. Med. 23, 249-258. doi: $10.1089 / \mathrm{acm} .2016 .0023$

McKenzie, C., Tan, J., Macia, L., and Mackay, C. R. (2017). The nutrition-gut microbiome-physiology axis and allergic diseases. Immunol. Rev. 278, 277-295. doi: 10.1111/imr.12556

Meng, J., Banerjee, S., Li, D., Sindberg, G. M., Wang, F., Ma, J., et al. (2015). Opioid exacerbation of gram-positive sepsis, induced by gut microbial modulation, is rescued by IL-17A neutralization. Sci. Rep. 5:10918. doi: 10.1038/srep 10918

Mi, G. L., Zhao, L., Qiao, D. D., Kang, W. Q., Tang, M. Q., and Xu, J. K. (2015). Effectiveness of Lactobacillus reuteri in infantile colic and colicky induced maternal depression: a prospective single blind randomized trial. Antonie Van Leeuwenhoek 107, 1547-1553. doi: 10.1007/s10482-015-0448-9

Mika, A., Day, H. E., Martinez, A., Rumian, N. L., Greenwood, B. N., Chichlowski, M., et al. (2017). Early life diets with prebiotics and bioactive milk fractions attenuate the impact of stress on learned helplessness behaviours and alter gene expression within neural circuits important for stress resistance. Eur. J. Neurosci. 45, 342-357. doi: 10.1111/ejn.13444

Minter, M. R., Hinterleitner, R., Meisel, M., Zhang, C., Leone, V., Zhang, X., et al. (2017). Antibiotic-induced perturbations in microbial diversity during postnatal development alters amyloid pathology in an aged APPSWE/PS1DeltaE9 murine model of Alzheimer's disease. Sci. Rep. 7:10411. doi: 10.1038/s41598017-11047-w

Moloney, R. D., Desbonnet, L., Clarke, G., Dinan, T. G., and Cryan, J. F. (2014). The microbiome: stress, health and disease. Mamm. Genome 25, 49-74. doi: 10.1007/s00335-013-9488-5

Montiel-Castro, A. J., Gonzalez-Cervantes, R. M., Bravo-Ruiseco, G., and PachecoLopez, G. (2013). The microbiota-gut-brain axis: neurobehavioral correlates, health and sociality. Front. Integr. Neurosci. 7:70. doi: 10.3389/fnint.2013.00070

Mu, C., Yang, Y., and Zhu, W. (2016). Gut microbiota: the brain peacekeeper. Front. Microbiol. 7:345. doi: 10.3389/fmicb.2016.00345

Murphy, T., Dias, G. P., and Thuret, S. (2014). Effects of diet on brain plasticity in animal and human studies: mind the gap. Neural Plast. 2014:563160. doi: $10.1155 / 2014 / 563160$

Neish, A. S., Pacifici, R., Mulle, J. G., Kraft, C. S., and Stephens, D. S. (2017). The microbiome: current and future view of an ancient paradigm. Future Microbiol. 12, 831-834. doi: $10.2217 /$ fmb-2017-2083 
Nemani, K., Hosseini Ghomi, R., McCormick, B., and Fan, X. (2015). Schizophrenia and the gut-brain axis. Prog. Neuro Psychopharmacol. Biol. Psychiatry 56, 155-160. doi: 10.1016/j.pnpbp.2014.08.018

Neufeld, K. M., Kang, N., Bienenstock, J., and Foster, J. A. (2011). Reduced anxiety-like behavior and central neurochemical change in germ-free mice. Neurogastroenterol. Motil. 23, 255-264. doi: 10.1111/j.1365-2982.2010.01 620.x

Neuman, H., Debelius, J. W., Knight, R., and Koren, O. (2015). Microbial endocrinology: the interplay between the microbiota and the endocrine system. FEMS Microbiol. Rev. 39, 509-521. doi: 10.1093/femsre/fuu010

Nicholson, J. K., Holmes, E., Kinross, J., Burcelin, R., Gibson, G., Jia, W., et al. (2012). Host-gut microbiota metabolic interactions. Science 336, 1262-1267. doi: $10.1126 /$ science. 1223813

Nishida, A. H., and Ochman, H. (2017). Rates of gut microbiome divergence in mammals. Mol. Ecol. 27, 1884-1897. doi: 10.1111/mec.14473

Noh, H., Jeon, J., and Seo, H. (2014). Systemic injection of LPS induces regionspecific neuroinflammation and mitochondrial dysfunction in normal mouse brain. Neurochem. Int. 69, 35-40. doi: 10.1016/j.neuint.2014.02.008

Ochoa-Reparaz, J., and Kasper, L. H. (2018). The microbiome and neurologic disease: past and future of a 2-way interaction. Neurotherapeutics 15, 1-4. doi: 10.1007/s13311-018-0604-9

Ochoa-Reparaz, J., Mielcarz, D. W., Ditrio, L. E., Burroughs, A. R., Foureau, D. M., Haque-Begum, S., et al. (2009). Role of gut commensal microflora in the development of experimental autoimmune encephalomyelitis. J. Immunol. 183, 6041-6050. doi: 10.4049/jimmunol.0900747

Ogbonnaya, E. S., Clarke, G., Shanahan, F., Dinan, T. G., Cryan, J. F., and O'Leary, O. F. (2015). Adult hippocampal neurogenesis is regulated by the microbiome. Biol. Psychiatry 78, e7-e9. doi: 10.1016/j.biopsych.2014.12.023

Ohland, C. L., Kish, L., Bell, H., Thiesen, A., Hotte, N., Pankiv, E., et al. (2013). Effects of Lactobacillus helveticus on murine behavior are dependent on diet and genotype and correlate with alterations in the gut microbiome. Psychoneuroendocrinology 38, 1738-1747. doi: 10.1016/j.psyneuen.2013.02.008

Ohsawa, K., Uchida, N., Ohki, K., Nakamura, Y., and Yokogoshi, H. (2015). Lactobacillus helveticus-fermented milk improves learning and memory in mice. Nutr. Neurosci. 18, 232-240. doi: 10.1179/1476830514Y.00000 00122

O’Mahony, S. M., Clarke, G., Borre, Y. E., Dinan, T. G., and Cryan, J. F. (2014). Serotonin, tryptophan metabolism and the brain-gut-microbiome axis. Behav. Brain Res. 277, 32-48. doi: 10.1016/j.bbr.2014.07.027

O'Mahony, S. M., Clarke, G., Dinan, T. G., and Cryan, J. F. (2017). Early-life adversity and brain development: is the microbiome a missing piece of the puzzle? Neuroscience 342, 37-54. doi: 10.1016/j.neuroscience.2015.09.068

O’Mahony, S. M., Hyland, N. P., Dinan, T. G., and Cryan, J. F. (2011). Maternal separation as a model of brain-gut axis dysfunction. Psychopharmacology 214, 71-88. doi: 10.1007/s00213-010-2010-9

O’Mahony, S. M., Marchesi, J. R., Scully, P., Codling, C., Ceolho, A. M., Quigley, E. M. M., et al. (2009). Early life stress alters behavior, immunity, and microbiota in rats: implications for irritable bowel syndrome and psychiatric illnesses. Biol. Psychiatry 65, 263-267. doi: 10.1016/j.biopsych.2008.06.026

Owen, L., and Corfe, B. (2017). The role of diet and nutrition on mental health and wellbeing. Proc. Nutr. Soc. 76, 425-426. doi: 10.1017/S00296651170 01057

Parashar, A., and Udayabanu, M. (2016). Gut microbiota regulates key modulators of social behavior. Eur. Neuropsychopharmacol. 26, 78-91. doi: 10.1016/j. euroneuro.2015.11.002

Partty, A., Kalliomaki, M., Wacklin, P., Salminen, S., and Isolauri, E. (2015). A possible link between early probiotic intervention and the risk of neuropsychiatric disorders later in childhood: a randomized trial. Pediatr. Res. 77, 823-828. doi: 10.1038/pr.2015.51

Paschos, G. K., and FitzGerald, G. A. (2017). Circadian clocks and metabolism: implications for microbiome and aging. Trends Genet. 33, 760-769. doi: 10.1016/j.tig.2017.07.010

Paulose, J. K., and Cassone, V. M. (2016). The melatonin-sensitive circadian clock of the enteric bacterium Enterobacter aerogenes. Gut Microbes 7, 424-427. doi: 10.1080/19490976.2016.1208892

Paulose, J. K., Wright, J. M., Patel, A. G., and Cassone, V. M. (2016). Human gut bacteria are sensitive to melatonin and express endogenous circadian rhythmicity. PLoS One 11:e0146643. doi: 10.1371/journal.pone.0146643
Penders, J., Thijs, C., Vink, C., Stelma, F. F., Snijders, B., Kummeling, I., et al. (2006). Factors influencing the composition of the intestinal microbiota in early infancy. Pediatrics 118, 511-521. doi: 10.1542/peds.2005-2824

Petrof, E. O., Claud, E. C., Gloor, G. B., and Allen-Vercoe, E. (2013). Microbial ecosystems therapeutics: a new paradigm in medicine? Benef. Microbes 4, 53-65. doi: 10.3920/BM2012.0039

Pimentel, M., Mathur, R., and Chang, C. (2013). Gas and the microbiome. Curr. Gastroenterol. Rep. 15:356. doi: 10.1007/s11894-013-0 356-y

Pirbaglou, M., Katz, J., de Souza, R. J., Stearns, J. C., Motamed, M., and Ritvo, P. (2016). Probiotic supplementation can positively affect anxiety and depressive symptoms: a systematic review of randomized controlled trials. Nutr. Res. 36, 889-898. doi: 10.1016/j.nutres.2016.06.009

Potgieter, M., Bester, J., Kell, D. B., and Pretorius, E. (2015). The dormant blood microbiome in chronic, inflammatory diseases. FEMS Microbiol. Rev. 39, 567591. doi: 10.1093/femsre/fuv013

Prinz, M., Tay, T. L., Wolf, Y., and Jung, S. (2014). Microglia: unique and common features with other tissue macrophages. Acta Neuropathol. 128, 319-331. doi: 10.1007/s00401-014-1267-1

Quigley, E. M. M. (2017). Microbiota-brain-gut axis and neurodegenerative diseases. Curr. Neurol. Neurosci. Rep. 17:94. doi: 10.1007/s11910-017-0802-6

Quirk, S. E., Williams, L. J., O'Neil, A., Pasco, J. A., Jacka, F. N., Housden, S., et al. (2013). The association between diet quality, dietary patterns and depression in adults: a systematic review. BMC Psychiatry 13:175. doi: 10.1186/1471-244X13- 175

Rao, A. V., Bested, A. C., Beaulne, T. M., Katzman, M. A., Iorio, C., Berardi, J. M., et al. (2009). A randomized, double-blind, placebo-controlled pilot study of a probiotic in emotional symptoms of chronic fatigue syndrome. Gut Pathog. 1:6. doi: 10.1186/1757-4749-1-6

Raybould, H. E. (2010). Gut chemosensing: interactions between gut endocrine cells and visceral afferents. Auton. Neurosci. 153, 41-46. doi: 10.1016/j.autneu. 2009.07.007

Rea, K., Dinan, T. G., and Cryan, J. F. (2016). The microbiome: a key regulator of stress and neuroinflammation. Neurobiol. Stress 4, 23-33. doi: 10.1016/j.ynstr. 2016.03.001

Rehfeld, J. F. (2014). Gastrointestinal hormones and their targets. Adv. Exp. Med. Biol. 817, 157-175. doi: 10.1007/978-1-4939-0897-4_7

Rhee, S. H., Pothoulakis, C., and Mayer, E. A. (2009). Principles and clinical implications of the brain-gut-enteric microbiota axis. Nat. Rev. Gastroenterol. Hepatol. 6, 306-314. doi: 10.1038/nrgastro.2009.35

Ridaura, V., and Belkaid, Y. (2015). Gut microbiota: the link to your second brain. Cell 161, 193-194. doi: 10.1016/j.cell.2015.03.033

Rieder, R., Wisniewski, P. J., Alderman, B. L., and Campbell, S. C. (2017). Microbes and mental health: a review. Brain Behav. Immun. 66, 9-17. doi: 10.1016/j.bbi. 2017.01.016

Robertson, R. C., Seira Oriach, C., Murphy, K., Moloney, G. M., Cryan, J. F., Dinan, T. G., et al. (2017). Omega-3 polyunsaturated fatty acids critically regulate behaviour and gut microbiota development in adolescence and adulthood. Brain Behav. Immun. 59, 21-37. doi: 10.1016/j.bbi.2016. 07.145

Roca-Saavedra, P., Mendez-Vilabrille, V., Miranda, J. M., Nebot, C., CardelleCobas, A., Franco, C. M., et al. (2017). Food additives, contaminants and other minor components: effects on human gut microbiota-a review. J. Physiol. Biochem. 74, 69-83. doi: 10.1007/s13105-017-0564-2

Rodrigues-Amorim, D., Rivera-Baltanas, T., Regueiro, B., Spuch, C., de Las Heras, M. E., Vazquez-Noguerol Mendez, R., et al. (2018). The role of the gut microbiota in schizophrenia: current and future perspectives. World J. Biol. Psychiatry doi: 10.1080/15622975.2018.1433878 [Epub ahead of print].

Rook, G. A. W. (2009). "Introduction: the changing microbial environment, Darwinian medicine and the hygiene hypothesis," in The Hygiene Hypothesis and Darwinian Medicine, ed. G. A. W. Rook (Berlin: Springer Science \& Business Media), 1-27.

Rook, G. A. W. (2013). Regulation of the immune system by biodiversity from the natural environment: an ecosystem service essential to health. Proc. Natl. Acad. Sci. U.S.A. 110, 18360-18367. doi: 10.1073/pnas.1313731110

Rook, G. A. W., Backhed, F., Levin, B. R., McFall-Ngai, M. J., and McLean, A. R. (2017). Evolution, human-microbe interactions, and life history plasticity. Lancet 390, 521-530. doi: 10.1016/S0140-6736(17)30566-4 
Rook, G. A. W., and Lowry, C. A. (2008). The hygiene hypothesis and psychiatric disorders. Trends Immunol. 29, 150-158. doi: 10.1016/J.It.2008.01.002

Rook, G. A. W., Lowry, C. A., and Raison, C. L. (2011). Lymphocytes in neuroprotection, cognition and emotion: is intolerance really the answer? Brain Behav. Immun. 25, 591-601. doi: 10.1016/j.bbi.2010.12.005

Rosas-Villegas, A., Sanchez-Tapia, M., Avila-Nava, A., Ramirez, V., Tovar, A. R., and Torres, N. (2017). Differential effect of sucrose and fructose in combination with a high fat diet on intestinal microbiota and kidney oxidative stress. Nutrients 9:E393. doi: 10.3390/nu9040393

Rothhammer, V., Borucki, D. M., Tjon, E. C., Takenaka, M. C., Chao, C. C., Ardura-Fabregat, A., et al. (2018). Microglial control of astrocytes in response to microbial metabolites. Nature 557, 724-728. doi: 10.1038/s41586-018-0119-x

Rudzki, L., and Szulc, A. (2018). "Immune Gate" of psychopathology-the role of gut derived immune activation in major psychiatric disorders. Front. Psychiatry 9:205. doi: $10.3389 /$ fpsyt.2018.00205

Sampson, T. R., Debelius, J. W., Thron, T., Janssen, S., Shastri, G. G., Ilhan, Z. E., et al. (2016). Gut microbiota regulate motor deficits and neuroinflammation in a model of parkinson's disease. Cell 167, 1469.e12-1480.e12. doi: 10.1016/j.cell. 2016.11.018

Sampson, T. R., and Mazmanian, S. K. (2015). Control of brain development, function, and behavior by the microbiome. Cell Host Microbe 17, 565-576. doi: 10.1016/j.chom.2015.04.011

Sanchez, B., Delgado, S., Blanco-Miguez, A., Lourenco, A., Gueimonde, M., and Margolles, A. (2017). Probiotics, gut microbiota, and their influence on host health and disease. Mol. Nutr. Food Res. 61:1600240. doi: 10.1002/mnfr. 201600240

Sandhu, K. V., Sherwin, E., Schellekens, H., Stanton, C., Dinan, T. G., and Cryan, J. F. (2017). Feeding the microbiota-gut-brain axis: diet, microbiome, and neuropsychiatry. Transl. Res. 179, 223-244. doi: 10.1016/j.trsl.2016. 10.002

Sandoval-Motta, S., Aldana, M., Martinez-Romero, E., and Frank, A. (2017). The human microbiome and the missing heritability problem. Front. Genet. 8:80. doi: 10.3389/fgene.2017.00080

Sarris, J., Logan, A. C., Akbaraly, T. N., Amminger, G. P., BalanzaMartinez, V., Freeman, M. P., et al. (2015). Nutritional medicine as mainstream in psychiatry. Lancet Psychiatry 2, 271-274. doi: 10.1016/S2215-0366(14) 00051-0

Schnorr, S. L., and Bachner, H. A. (2016). Integrative therapies in anxiety treatment with special emphasis on the gut microbiome. Yale J. Biol. Med. 89, $397-422$.

Shanahan, F. (2009). "Linking lifestyle with microbiota and risk of chronic inflammatory disorders," in The Hygiene Hypothesis and Darwinian Medicine, ed. G. A. W. Rook (Berlin: Springer Science \& Business Media), 93-102. doi: 10.1007/978-3-7643-8903-1_5

Shanahan, F., van Sinderen, D., O’Toole, P. W., and Stanton, C. (2017). Feeding the microbiota: transducer of nutrient signals for the host. Gut 66, 1709-1717. doi: 10.1136/gutjnl-2017-313872

Sharon, G., Sampson, T. R., Geschwind, D. H., and Mazmanian, S. K. (2016). The central nervous system and the gut microbiome. Cell 167, 915-932. doi: 10.1016/j.cell.2016.10.027

Shen, Y., Xu, J., Li, Z., Huang, Y., Yuan, Y., Wang, J., et al. (2018). Analysis of gut microbiota diversity and auxiliary diagnosis as a biomarker in patients with schizophrenia: a cross-sectional study. Schizophr. Res. doi: 10.1016/j.schres. 2018.01.002 [Epub ahead of print].

Singh, R. K., Chang, H. W., Yan, D., Lee, K. M., Ucmak, D., Wong, K., et al. (2017). Influence of diet on the gut microbiome and implications for human health. J. Transl. Med. 15:73. doi: 10.1186/s12967-017-1175-y

Skosnik, P. D., and Cortes-Briones, J. A. (2016). Targeting the ecology within: the role of the gut-brain axis and human microbiota in drug addiction. Med. Hypotheses 93, 77-80. doi: 10.1016/j.mehy.2016.05.021

Skypala, I. J. (2017). When nutrition and allergy collide: the rise of anaphylaxis to plant foods. Curr. Opin. Allergy Clin. Immunol. 17, 338-343. doi: 10.1097/aci. 0000000000000387

Slyepchenko, A., Maes, M., Jacka, F. N., Köhler, C. A., Barichello, T., McIntyre, R. S., et al. (2017). Gut microbiota, bacterial translocation, and interactions with diet: pathophysiological links between major depressive disorder and non-communicable medical comorbidities. Psychother. Psychosom. 86, 31-46. doi: $10.1159 / 000448957$
Slykerman, R. F., Thompson, J., Waldie, K. E., Murphy, R., Wall, C., and Mitchell, E. A. (2017). Antibiotics in the first year of life and subsequent neurocognitive outcomes. Acta Paediatr. 106, 87-94. doi: 10.1111/apa.13613

Smith, K., and Torres, C. D. (2014). Mental health: a world of depression. Nature 515:181. doi: 10.1038/515180a

Smith, P. A. (2015). The tantalizing links between gut microbes and the brain. Nature 526, 312-314. doi: 10.1038/526312a

Smythies, L. E., and Smythies, J. R. (2014). Microbiota, the immune system, black moods and the brain-melancholia updated. Front. Hum. Neurosci. 8:720. doi: 10.3389/fnhum.2014.00720

Sonnenburg, E. D., Samuel, A., Smits Mikhail Tikhonov Steven, K., Higginbottom Ned, S., and Wingreen Sonnenburg, J. L. (2016). Diet-induced extinctions in the gut microbiota compound over generations. Nature 529, 212-215. doi: $10.1038 /$ nature16504

Statovci, D., Aguilera, M., MacSharry, J., and Melgar, S. (2017). The impact of western diet and nutrients on the microbiota and immune response at mucosal interfaces. Front. Immunol. 8:838. doi: 10.3389/fimmu.2017.00838

Steenbergen, L., Sellaro, R., van Hemert, S., Bosch, J. A., and Colzato, L. S. (2015). A randomized controlled trial to test the effect of multispecies probiotics on cognitive reactivity to sad mood. Brain Behav. Immun. 48, 258-264. doi: 10.1016/j.bbi.2015.04.003

Strachan, D. P. (1989). Hay fever, hygiene, and household size. Br. Med. J. 299, 1259-1260. doi: 10.1136/bmj.299.6710.1259

Strati, F., Cavalieri, D., Albanese, D., De Felice, C., Donati, C., Hayek, J., et al. (2017). New evidences on the altered gut microbiota in autism spectrum disorders. Microbiome 5:24. doi: 10.1186/s40168-017-0242-1

Stumpf, R. M., Wilson, B. A., Rivera, A., Yildirim, S., Yeoman, C. J., Polk, J. D., et al. (2013). The primate vaginal microbiome: comparative context and implications for human health and disease. Am. J. Phys. Anthropol. 152(Suppl. 57), 119-134. doi: 10.1002/ajpa.22395

Sudo, N. (2006). Stress and gut microbiota: does postnatal microbial colonization programs the hypothalamic-pituitary-adrenal system for stress response? Int. Congr. Ser. 1287, 350-354. doi: 10.1016/j.ics.2005.12.019

Sudo, N. (2014). Microbiome, HPA axis and production of endocrine hormones in the gut. Adv. Exp. Med. Biol. 817, 177-194. doi: 10.1007/978-1-4939-0897-4_8

Sudo, N., Chida, Y., and Kubo, C. (2005). Postnatal microbial colonization programs the hypothalamic-pituitary-adrenal system for stress response in mice. J. Psychosom. Res. 58, S60-S60.

Suez, J., Korem, T., Zeevi, D., Zilberman-Schapira, G., Thaiss, C. A., Maza, O., et al. (2014). Artificial sweeteners induce glucose intolerance by altering the gut microbiota. Nature 514, 181-186. doi: 10.1038/nature13793

Taylor, W. R., and Takemiya, K. (2017). hypertension opens the flood gates to the gut microbiota. Circ. Res. 120, 249-251. doi: 10.1161/CIRCRESAHA.116. 310339

Terenius, L. (2000). From opiate pharmacology to opioid peptide physiology. Ups. J. Med. Sci. 105, 1-15. doi: 10.1517/03009734000000043

Thaiss, C. A., Levy, M., Suez, J., and Elinav, E. (2014). The interplay between the innate immune system and the microbiota. Curr. Opin. Immunol. 26, 41-48. doi: 10.1016/j.coi.2013.10.016

Thaiss, C. A., Nobs, S. P., and Elinav, E. (2017). NFIL-trating the host circadian rhythm-microbes fine-tune the epithelial clock. Cell Metab. 26, 699-700. doi: 10.1016/j.cmet.2017.10.014

Thion, M. S., Low, D., Silvin, A., Chen, J., Grisel, P., Schulte-Schrepping, J., et al. (2017). Microbiome influences prenatal and adult microglia in a sex-specific manner. Cell 172, 500.e16-516.e16. doi: 10.1016/j.cell.2017.11.042

Tlaskalova-Hogenova, H., Tuckova, L., Mestecky, J., Kolinska, J., Rossmann, P., Stepankova, R., et al. (2005). Interaction of mucosal microbiota with the innate immune system. Scand. J. Immunol. 62(Suppl. 1), 106-113. doi: 10.1111/j.13653083.2005.01618.x

Tomasik, J., Yolken, R. H., Bahn, S., and Dickerson, F. B. (2015). Immunomodulatory effects of probiotic supplementation in schizophrenia patients: a randomized, placebo-controlled trial. Biomark Insights 10, 47-54. doi: 10.4137/BMI.S22007

Tordesillas, L., Berin, M. C., and Sampson, H. A. (2017). Immunology of food allergy. Immunity 47, 32-50. doi: 10.1016/j.immuni.2017.07.004

Turna, J., Grosman Kaplan, K., Anglin, R., and Van Ameringen, M. (2016). "What's bugging the gut in Ocd?" a review of the gut microbiome in obsessivecompulsive disorder. Depress Anxiety 33, 171-178. doi: 10.1002/da.22454 
Two, A. M., Nakatsuji, T., Kotol, P. F., Arvanitidou, E., Du-Thumm, L., Hata, T. R., et al. (2016). The cutaneous microbiome and aspects of skin antimicrobial defense system resist acute treatment with topical skin cleansers. J. Invest. Dermatol. 136, 1950-1954. doi: 10.1016/j.jid.2016.06.612

Ulvestad, E. (2009). Cooperation and conflict in host-microbe relations. APMIS 117, 311-322. doi: 10.1111/j.1600-0463.2009.02457.x

van de Wouw, M., Schellekens, H., Dinan, T. G., and Cryan, J. F. (2017). Microbiota-gut-brain axis: modulator of host metabolism and appetite. J. Nutr. 147, 727-745. doi: 10.3945/jn.116.240481

van den Hoogen, W. J., Laman, J. D., and t Hart, B. A. (2017). Modulation of multiple sclerosis and its animal model experimental autoimmune encephalomyelitis by food and gut microbiota. Front. Immunol. 8:1081. doi: 10.3389/fimmu.2017.01081

Velmurugan, G., Ramprasath, T., Gilles, M., Swaminathan, K., and Ramasamy, S. (2017). Gut microbiota, endocrine-disrupting chemicals, and the diabetes epidemic. Trends Endocrinol. Metab. 28, 612-625. doi: 10.1016/j.tem.2017. 05.001

Vogtmann, E., Flores, R., Yu, G., Freedman, N. D., Shi, J., Gail, M. H., et al. (2015). Association between tobacco use and the upper gastrointestinal microbiome among Chinese men. Cancer Causes Control 26, 581-588. doi: 10.1007/s10552015-0535-2

von Mutius, E. (2017). The shape of the microbiome in early life. Nat. Med. 23, 274-275. doi: 10.1038/nm.4299

Voreades, N., Kozil, A., and Weir, T. L. (2014). Diet and the development of the human intestinal microbiome. Front. Microbiol. 5:494. doi: 10.3389/fmicb.2014. 00494

Vuong, H. E., Yano, J. M., Fung, T. C., and Hsiao, E. Y. (2017). The microbiome and host behavior. Ann. Rev. Neurosci. 40, 21-49. doi: 10.1146/annurev-neuro072116-031347

Vyas, U., and Ranganathan, N. (2012). Probiotics, prebiotics, and synbiotics: gut and beyond. Gastroenterol. Res. Pract. 2012:872716. doi: 10.1155/2012/872716

Wall, R., Cryan, J. F., Ross, R. P., Fitzgerald, G. F., Dinan, T. G., and Stanton, C. (2014). Bacterial neuroactive compounds produced by psychobiotics. Adv. Exp. Med. Biol. 817, 221-239. doi: 10.1007/978-1-4939-0897-4_10

Wall, R., Marques, T. M., O’Sullivan, O., Ross, R. P., Shanahan, F., Quigley, E. M. M., et al. (2012). Contrasting effects of bifidobacterium breve NCIMB 702258 and Bifidobacterium breve DPC 6330 on the composition of murine brain fatty acids and gut microbiota. Am. J. Clin. Nutr. 95, 1278-1287. doi: 10.3945/ajcn.111.026435

Wallace, B. D., and Redinbo, M. R. (2013). The human microbiome is a source of therapeutic drug targets. Curr. Opin. Chem. Biol. 17, 379-384. doi: 10.1016/j. cbpa.2013.04.011

Wallace, C. J. K., and Milev, R. (2017). The effects of probiotics on depressive symptoms in humans: a systematic review. Ann. Gen. Psychiatry 16:14. doi: 10.1186/s12991-017-0138-2

Wampach, L., Heintz-Buschart, A., Hogan, A., Muller, E. E. L., Narayanasamy, S., Laczny, C. C., et al. (2017). Colonization and succession within the human gut microbiome by archaea, bacteria, and microeukaryotes during the first year of life. Front. Microbiol. 8:738. doi: 10.3389/fmicb.2017.00738

Wang, F., and Roy, S. (2017). Gut homeostasis, microbial dysbiosis, and opioids. Toxicol. Pathol. 45, 150-156. doi: 10.1177/0192623316679898

Wang, L., Christophersen, C. T., Sorich, M. J., Gerber, J. P., Angley, M. T., and Conlon, M. A. (2012). Elevated fecal short chain fatty acid and ammonia concentrations in children with autism spectrum disorder. Dig. Dis. Sci 57, 2096-2102. doi: 10.1007/s10620-012-2167-7

Wang, T., Hu, X., Liang, S., Li, W., Wu, X., Wang, L., et al. (2015). Lactobacillus fermentum NS9 restores the antibiotic induced physiological and psychological abnormalities in rats. Benef. Microbes 6, 707-717. doi: 10.3920/BM2014.0177

Westfall, S., Lomis, N., Kahouli, I., Dia, S. Y., Singh, S. P., and Prakash, S. (2017). Microbiome, probiotics and neurodegenerative diseases: deciphering the gut brain axis. Cell. Mol. Life Sci. 74, 3769-3787. doi: 10.1007/s00018-0172550-9
Williamson, P. S. (2017). A brief overview and comparison of global fiber regulations. Cereal Foods World 62, 95-97. doi: 10.1094/Cfw-62-3-0095

Wood, J. D. (2007). Neuropathophysiology of functional gastrointestinal disorders. World J. Gastroenterol. 13, 1313-1332. doi: 10.3748/wjg.v13.i9.1313

Worthington, J. J., Reimann, F., and Gribble, F. M. (2018). Enteroendocrine cellssensory sentinels of the intestinal environment and orchestrators of mucosal immunity. Mucosal Immunol. 11, 3-20. doi: 10.1038/mi.2017.73

Wu, G. D., Chen, J., Hoffmann, C., Bittinger, K., Chen, Y. Y., Keilbaugh, S. A., et al. (2011). Linking long-term dietary patterns with gut microbial enterotypes. Science 334, 105-108. doi: 10.1126/science.1208344

Wu, J., Zhang, Y., Yang, H., Rao, Y., Miao, J., and Lu, X. (2016). Intestinal microbiota as an alternative therapeutic target for epilepsy. Can. J. Infect. Dis. Med. Microbiol. 2016:9032809. doi: 10.1155/2016/9032809

Yang, C., Gao, J., Zhang, J., and Luo, A. L. (2017). Enterochromaffin cells in the gut: a distant regulator of brain function? Gut 67, 1557-1558. doi: 10.1136/gutjnl2017-315406

Yang, T., and Zubcevic, J. (2017). Gut-brain axis in regulation of blood pressure. Front. Physiol. 8:845. doi: 10.3389/fphys.2017.00845

Yang, Y., Tian, J., and Yang, B. (2018). Targeting gut microbiome: a novel and potential therapy for autism. Life Sci. 194, 111-119. doi: 10.1016/j.lfs.2017. 12.027

Yano, J. M., Yu, K., Donaldson, G. P., Shastri, G. G., Ann, P., Ma, L., et al. (2015). Indigenous bacteria from the gut microbiota regulate host serotonin biosynthesis. Cell 161, 264-276. doi: 10.1016/j.cell.2015.02.047

Yatsunenko, T., Rey, F. E., Manary, M. J., Trehan, I., Dominguez-Bello, M. G., Contreras, M., et al. (2012). Human gut microbiome viewed across age and geography. Nature 486, 222-227. doi: 10.1038/nature11053

Yolken, R., and Dickerson, F. (2017). The role of the microbiome in bipolar disorder-a new model. Biol. Psychiatry 81, S313-S314. doi: 10.1016/j.biopsych. 2017.02.839

Young, V. B. (2017). The role of the microbiome in human health and disease: an introduction for clinicians. BMJ 356:j831. doi: 10.1136/bmj.j831

Zarrinpar, A., Chaix, A., Yooseph, S., and Panda, S. (2014). Diet and feeding pattern affect the diurnal dynamics of the gut microbiome. Cell Metab. 20, 1006-1017. doi: 10.1016/j.cmet.2014.11.008

Zepf, F. D., Stewart, R. M., Hood, S., and Guillemin, G. J. (2016). Great expectations: nutritional medicine as a mainstream in clinical psychiatry and weighing opportunities against risks. Med. Hypotheses 88, 68-69. doi: 10.1016/ j.mehy.2016.01.004

Zhang, F., Cui, B., He, X., Nie, Y., Wu, K., Fan, D., et al. (2018). Microbiota transplantation: concept, methodology and strategy for its modernization. Protein Cell 9, 462-473. doi: 10.1007/s13238-018-0541-8

Zhao, H., Shi, Y., Luo, X., Peng, L., Yang, Y., and Zou, L. (2017). The effect of fecal microbiota transplantation on a child with tourette syndrome. Case Rep. Med. 2017:6165239. doi: 10.1155/2017/6165239

Zhao, L., and Zhang, C. (2017). Microbiome: keeping rhythm with your gut. Nat. Microbiol. 2:16273. doi: 10.1038/nmicrobiol.2016.273

Zheng, P., Zeng, B., Zhou, C., Liu, M., Fang, Z., Xu, X., et al. (2016). Gut microbiome remodeling induces depressive-like behaviors through a pathway mediated by the host's metabolism. Mol. Psychiatry 21, 786-796. doi: 10.1038/ mp. 2016.44

Conflict of Interest Statement: The authors declare that the research was conducted in the absence of any commercial or financial relationships that could be construed as a potential conflict of interest.

Copyright (c) 2018 Liang, Wu and Jin. This is an open-access article distributed under the terms of the Creative Commons Attribution License (CC BY). The use, distribution or reproduction in other forums is permitted, provided the original author(s) and the copyright owner(s) are credited and that the original publication in this journal is cited, in accordance with accepted academic practice. No use, distribution or reproduction is permitted which does not comply with these terms. 